\title{
A liquid biopsy platform for detecting gene-gene fusions as glioma diagnostic
}

\section{biomarkers and drug targets}

3

\begin{abstract}
$\underline{\text { Abstract }}$
Gliomas account for about $80 \%$ of all malignant brain tumours. Diagnosis is achieved by radiographic imaging followed by tumour resection, to determine tumour cell type, grade and molecular characteristics. Glioblastoma multiforme (GBM) is the most common type of glioma, and is uniformly fatal. The median survival of treated GBM patients is $12-15$ months. Standard modalities of therapy are unselective and include surgery, radiation therapy and chemotherapy, while precision medicine has yet to demonstrate improvements in disease outcome. We therefore selected GBM as a model to develop a precision medicine methodology for monitoring patients using blood plasma circulating cell-free DNA (cfDNA). Currently, tumour heterogeneity, clonal diversity and mutation acquisition are the major impedances for tailoring personalized therapy in gliomas in general, and particularly in GBM. Thus, a liquid biopsy diagnostics platform based on cfDNA sequencing may improve treatment outcome for GBM patients, by guiding therapy selection. In this study, we processed from 27 patients with glioma, 27 plasma samples for cfDNA isolation and 5 tissue biopsy samples for tumour DNA isolation. From a control group of 14 healthy individuals, 14 plasma samples were processed for cfDNA isolation. In glioma patients, cfDNA concentration was elevated compared to controls. Point mutations found in glioma tissue biopsies were also found in the cfDNA samples (95\% identity). Finally, we identified novel chimeric genes (gene-gene fusions) in both tumour and cfDNA samples. These fusions are predicted to alter protein interaction networks, by removing tumour suppressors and adding oncoproteins. Indeed, several of these fusions are potential drug targets, particularly, NTRK or ROS1 fusions, specifically for crizotinib analogues (like entrectinib and larotrectinib) with enhanced penetration of the central nervous system. Taken together, our results demonstrate that novel druggable targets in gliomas can be identified by liquid biopsy using cfDNA in patient plasma. These results open new perspectives and abilities of precision medicine in GBM.
\end{abstract}


Gliomas are primary malignant brain tumours that account for about $30 \%$ of all brain tumours and $80 \%$ of malignant brain tumours ${ }^{1-3}$. Glioblastoma multiforme (GBM) is the most common type of glioma, and is uniformly fatal; the median survival of treated patients is approximately $12-15$ months ${ }^{4,5,6}$. The gold standard method for detecting gliomas is radiographic evaluation by magnetic resonance imaging (MRI) scanning s,7,8 $^{3,3}$ followed by tissue diagnosis attained either by biopsy or during surgery. Tissue sampling must be obtained to determine tumour cell type, histologic grade and molecular characteristics ${ }^{7,9}$. The MRI contrast-enhancing region of the tumour is the target for surgical resection as part of GBM treatment ${ }^{10}$, which includes combined chemo-radiation therapy. In about $40 \%$ of GBM, $O^{6}$-methylguanine DNA methyltransferase (MGMT) promoter is methylated. This renders the cancer more susceptible to temozolomide, an alkylating agent that methylates DNA, and that constitutes a standard chemotherapy for $\mathrm{GBM}^{11}$. Current methods for tumour monitoring (e.g., MRI and CT) cannot provide real time actionable information for determining therapy response or for evolving the molecular landscape of the heterogeneous cancer cell population ${ }^{12}$. Furthermore, even a more precise diagnostic method such as molecular analysis of tumour biopsy may not entirely represent a heterogeneous tumour, or newly acquired mutations during the course of the disease ${ }^{13,14}$. A liquid biopsy platform that uses circulating cell-free DNA (cfDNA) may overcome the limitations posed by glioma tumour heterogeneity, and may provide a diagnostic means, and possibly even guide precision medicine for $\mathrm{GBM}^{12,15,16}$.

Liquid biopsy is a newly emerging non-invasive cancer diagnostic technique that potentially provides an alternative to surgical biopsies. Liquid biopsy provides various information about a tumour from simple blood, urine, saliva, serum or plasma samples ${ }^{13,17-20}$. This technique uses cells or cell components circulating in blood or urine, such as circulating cell-free DNA(cfDNA) ${ }^{21,22}$, cell-free RNA(cfRNA) $)^{23-28}$, extracellular vesicles $^{29-31}$, circulating proteins ${ }^{32,33}$ and circulating tumour cells ${ }^{34-40}$. These components are continuously released from the tumour and healthy tissues into the bloodstream as a result of secretion, rapid apoptosis and necrosis ${ }^{41,42}$. These moieties can be screened for tumour specific markers that may be useful in cancer diagnosis, monitoring or prognosis. ${ }^{17,19,43}$

CfDNA constitutes free-floating small fragments of DNA in the blood plasma, which result from apoptotic cell death ${ }^{44}$. Although sparsely studied, remarkably elevated cfDNA has been documented in patients with solid tumours compared to those with non-neoplastic diseases ${ }^{32,45-47}$. Of all the cfDNA fragments present in a cancer patient's plasma, 85\% are 166-bp, 10\% are 332-bp and 5\% are 498-bp in length ${ }^{21}$ (Fig. 1). By contrast, larger fragments of cfDNA, $\sim 10,000 \mathrm{bp}$ in length, in the blood of cancer patients, are most likely of necrotic origin ${ }^{41,42,48-50}$ (Fig. 1). Using next-generation sequencing analysis, Snyder et al., ${ }^{51}$ identified some bias in the cfDNA fragmentation pattern, which was affected by nucleosome occupancy and transcription factor binding. The latter protects DNA from nuclease digestion during apoptosis, potentially providing a clue to cell type origin ${ }^{51}$. CfDNA has been found in patients with diverse types of neoplasms and metastatic disease $\mathrm{s}^{52,53}$. This has led to the identification of specific genetic markers bearing varying degrees of specificity and sensitivity. However, these markers have yet to prove useful in diagnostics ${ }^{54-61}$. Deep sequencing of plasma 
DNA in patients with various cancers suggests that cfDNA is representative of the entire tumour genome, and can be an accurate reflection of tumour heterogeneity and acquired mutations ${ }^{13,14,61-63}$. As such, in breast, colon, ovarian and melanoma cancers, cfDNA levels have been found to be clinically useful, with an inverse relation between cfDNA levels and survival ${ }^{55,64-68}$. By contrast, a major problem arises in the analysis of cfDNA from brain tumours due to low cfDNA levels in plasma. The unique localization and anatomic features of the brain ${ }^{54}$, appear to reduce the frequency of detectable cfDNA by $60 \%$ in medulloblastoma, and by $90 \%$ in low-grade glioma, compared to other advanced systemic tumours. This is substantially lower than the levels detected in colon, breast, lung, prostate, renal and thyroid cancers ${ }^{69-72}$ Thus, detecting cfDNA in glioma samples for clinical implementation remains a complex challenge ${ }^{54}$.

Precision medicine in glioma is in its infancy. Only a handful of mutations have been associated with disease type and prognosis, and no mutations are known to guide treatment modality. Thus, the World Health Organization presently classifies tumours of the central nervous system (CNS) based on their histological and molecular parameters, and on associations of mutations with disease prognosis and therapy ${ }^{73,74}$. However, these mutations have not been shown to guide precision medicine treatment of glioma. Diagnostic genes in brain tumours include isocitrate dehydrogenase (IDH), H3K27M, RELA fusion, wingless (WNT)-activated, sonic hedgehog (SHH)-activated and $C 19 M C$-altered ${ }^{75-78}$. A typical molecular signature that was extensively studied in oligodendroglial tumours is a chromosomal $1 \mathrm{p} / 19 \mathrm{q}$ co-deletion ${ }^{79-81}$. The exclusive presence of the $1 \mathrm{p} / 19 \mathrm{q}$ co-deletion in oligodendroglial tumours renders it a required biomarker for oligodendroglioma diagnosis, including hTERT promoter mutation ${ }^{82-84}$.

In regard to fusion genes as molecular markers, chromosomal aberrations play a crucial role in the initial steps of tumorigenesis ${ }^{85-88}$. This is especially true for translocations and their corresponding gene fusions $^{89-92}$, as they disrupt cellular regulatory mechanisms. These fusion genes are highly tissue specific and can be used as effective biomarkers in cancer diagnosis ${ }^{85-88,93,94}$. For example, TMPRSS2-ERG fusion genes have been detected in $40-80 \%$ of prostate cancers ${ }^{89-91}$. Moreover, the $B C R-A B L$ fusion gene is most commonly observed in CML. ${ }^{92}$ Overall, around $90 \%$ of lymphomas and nearly half of all forms of leukaemia harbour translocation-induced gene fusions. ${ }^{95}$ The $E M L 4-A L K$ gene fusion plays a crucial role in the development of epithelial cancers and lung cancer ${ }^{96}$, while the C11orf95-RELA fusion is characteristic of ependymoma grade II and grade III tumours (World Health Organization classification) ${ }^{73}$. Thus, the presence of the C11orf95-RELA fusion gene serves as an important biomarker for glioma subtype diagnosis ${ }^{87}$. Additional fusion genes may also serve as novel molecular markers for cancer diagnosis, yet their detection in liquid biopsy has not been systematically demonstrated, particularly in brain tumours.

Current technologies such as next-generation sequencing and digital droplet PCR can be applied with

107 high sensitivity towards rare mutation detection ${ }^{97-103}$, and can thus be used for identifying recurrent translocations and gene fusions in many cancer types including gliomas ${ }^{104-107}$. We have collected more than

10940,000 unique fusion transcripts (of more than 40 cancer types) in our ChiTaRS-5.0 database of Chimeric 110 Transcripts and RNA-Seq data ${ }^{108,109}$. This is the largest collection of chimeric transcripts (of cancer 111 chromosomal translocations and RNA trans-splicing) known today, including sense-antisense transcripts (SaS 
112 chimeras) ${ }^{109}$. Moreover, we have collated data on 1,207 known druggable fusion genes from PubMed articles

113 using our text-mining method, ProtFus ${ }^{110}$. In the present study we sequenced cfDNA of glioma patients; and

114 assessed plasma concentration, mutation patterns and novel fusion genes. By comparing to our existing fusion

115 database, we identified potential liquid biopsy biomarkers, and also drug targets and their corresponding

116 druggable fusions. The findings may help guide precision medicine in glioma therapy.

118 Results

119 Elevated cfDNA concentration in the plasma of glioma patients. We hypothesized that cfDNA concentration

120 might differ between individuals with gliomas and a non-cancer cohort. Thus, we collected 14 blood samples

121 from healthy controls and 27 blood samples from patients with gliomas (25 glioblastoma, 2 low-grade glioma).

122 The latter were matched to 27 brain biopsies of the same patients. For each patient, we extracted cfDNA from 123 plasma, genomic DNA (gDNA) from white blood cells (WBC), and tumour DNA (tDNA) from brain biopsies.

124 First, we assessed the cfDNA plasma concentration in the control cohort as ranging from 0 to $7.62 \mathrm{ng}$ per $\mathrm{ml}$ of 125 plasma (Fig. 2). Next, we isolated cfDNA in 26 of 27 samples of glioma patients, and achieved a 96\% 126 sensitivity level. The Qubit concentrations of cfDNA in these 26 patients ranged between 12.6ng and 137ng per $127 \mathrm{ml}$ of plasma (Fig. 2). Thus, all the patients had concentrations that were higher than those of all of the control 128 group (p-value $<0.0001$, $\mathrm{t}$-test). Next, we examined the size of the cfDNA molecules in all the samples. The 129 Bioanalyzer DNA High Sensitivity assay showed that in all 26 glioma patients, and also in all 14 healthy control 130 samples, cfDNA had a major peak at, or close to, 166bp (accounting for 85\% of the circulating cfDNA) and a 131 smaller peak at, or close to, 332bp (accounting for 10\% of the cfDNA; Fig. 3A). This concurs with the reference 132 sizes of cfDNA fragments in plasma ${ }^{21,111}$. Moreover, the cfDNA sequencing library peak was measured at $133291 \mathrm{bp}$, which indicates successful ligation of a 125bp adapter to 166bp cfDNA (Fig. 3B). Thus, a liquid biopsy 134 methodology can generate high quality results, enabling analysis of the cfDNA that is likely derived from 135 apoptotic cells (rather than necrosis). Accordingly, overall plasma cfDNA levels appear to discriminate a 136 tumour-bearing cohort (including patients with brain tumours) from a control cohort.

138 Mutation analysis of glioma cfDNA data. To confirm that the elevated cfDNA in the plasma of patients with 139 glioma is derived from cancer cells, we tested for the presence of mutations in both cfDNA and tDNA. We 140 sequenced 23 cfDNA samples (14 glioma and 9 controls) using a whole genome sequencing procedure (see 141 Materials and Methods) with 5x-10x coverage (at least 50 million paired-end (PE) reads per sample). In 142 addition, for five glioma samples, we sequenced their respective tDNA (10x coverage, 60 million PE reads) and 143 normal genomic DNA (from WBC) ( 60 million PE reads). We first removed the SNPs present in gDNA, then 144 sorted mutations into "cfDNA only", "tDNA only", and "both cfDNA and gDNA". We found for all five GBM 145 patients, namely \#GB1, \#GB3, \#GB5, \#GB7 and \#GB13, shared mutations between their cfDNA and tDNA, 146 with $90 \%$ selectivity and $80 \%$ sensitivity (FDR $<1 \%$, Table 1 ). These results indicate that in GBM, cfDNA 147 derives from the brain tumours (presumably, efflux from extracellular space into the plasma). 
Next, we extended the top-58 selected genes that are commonly mutated in gliomas, by those that were listed in three current studies in cfDNA in glioma ${ }^{112-114}$. Remarkably, for all the patients, the distributions of a number of mutations across the top-58 mutated genes in gliomas were highly conserved (FDR $<1 \%$, Fig. 5). This indicates that mutation distribution in cfDNA coincided with glioma type and grade. As a result, of these 58 genes, a total of 34(58\%), 38(65\%), 20(34\%), 27(46\%) and 39(67\%) genes were identified as mutated in both cfDNA and tDNA of our glioma patients i.e. \#GB1, \#GB3, \#GB5, \#GB7 and \#GB13, respectively (Table 2). These mutated genes included TP53, which encodes a protein that acts as a tumour suppressor in many cancer types including glioma $^{94}$; and the $I D H I$ mutation, which correlates negatively with glioma grades II to IV. The IDHImutation is detected at the rates of $77 \%, 55 \%$ and $6 \%$, for grades II, III and IV glioma, respectively ${ }^{115-120}$. Due to these unique characteristics, the $I D H 1$ mutation serves as a biomarker in the diagnosis and prognosis of glioma $115,121,122$. These results indicate that our liquid biopsy methodology captures a broad spectrum of known glioma mutations at similar incidence rates as in the tumour biopsies. cfDNA concentrations among low-grade and healthy controls than among high-grade glioma patients. This is presumably due to low numbers of necrotic and apoptotic cells in the former ${ }^{41,42,44}$. This finding suggests a potential sensitivity level for discovering high-grade gliomas using a simple cfDNA concentration test. We examined the possibility of classifying high-grade gliomas using mutations in cfDNA, for the diagnosis of GBM. Accordingly, we selected the 50 most frequently mutated genes from the current study of the mutation landscape in The Cancer Genome Atlas (TCGA) GBM dataset (PanCancer datasets, 291 GBM samples) ${ }^{123}$. Of these 50 genes, $21(42 \%), 26(52 \%), 13(26 \%), 22(44 \%)$ and 25(50\%) were also mutated in our GBM patients: \#GB1, \#GB3, \#GB5, \#GB7 and \#GB13, respectively (Table 3). As shown in Table 3, in addition to the most common glioblastoma-related genes, like IDH1 and TP53, we found mutations in the BRAF and EGFR genes,

171 which are recognized for their involvement in glioma tumour progression ${ }^{124,125}$. These results indicate that mutations found in cfDNA correspond to mutations in tumours, with $95 \%$ specificity, such that we were able to distinguish high-grade glioma types of tumours.

Next, we compared the somatic high impact mutations that were commonly shared between cfDNA and tDNA in our five patients to mutation landscape data of GBM from four studies ${ }^{112-114,123}$ (Tables 2 and 3). We validated these mutations using Sanger sequencing (Fig. 11). Additionally, we found that cfDNA produces a high-level profiling of somatic mutations in all GBM patients. Particularly, we found mutations in genes that are strongly involved in GBM, i.e. EGFR (3' UTR variant, intron variant, downstream gene variant), IDH1 (upstream gene variant, intron variant, downstream gene variant), PDGFRA (3'UTR variant, intron variant, downstream gene variant, upstream gene variant), PIK3CA (intron variant, upstream gene variant), PIK3R1 (upstream gene variant, downstream gene variant) and TP53 (upstream gene variant, intron variant, downstream gene variant). Finally, we found that tumour-suppressors were mostly removed from the gliomas by missense 

mutations that differentiate glioma patients from patients with other tumour types.

\section{6}

187

Fusion gene analysis. We hypothesized that fusion genes may contribute to glioma tumour formation, in addition to the point mutations described above, and that specific fusion vs. mutation combinations may be unique to glioma. We analysed DNA sequences from 20 normal samples, 18 of 20 glioma samples and seven tDNA and WBC gDNA of TCGA GBM patients. We searched for fusions, using our ChiTaRS 5.0 reference database (http://chitars.md.biu.ac.il/) ${ }^{126}$. Fig. 6 shows the top twenty gene fusions identified in tDNA, but not in the gDNA of TCGA GBM patients \#321970, \#265132, \#272523, \#265135 and \#065411. On the contrary, in TCGA GBM patients \#022485 and \#151444, these top twenty gene fusions were identified in gDNA but not in their respective tDNA. Comparing these twenty fusions with cfDNA, tDNA and gDNA from five GBM patients identified four unique gene fusions, i.e. APOA2-GPR160 (\#GB1), CASP8-PCGF5 (\#GB5), NEMF-S100A2 (\#GB7, \#GB13) and LINC01006-ALB (\#GB7, \#GB13) in cfDNA and tDNA, but not in the respective gDNA (Fig. 7). Next, we compared cfDNA of nine GBM patients and nine healthy controls (Fig. 8). Interestingly, the fusions that were identified in the cfDNA of the nine GBM patients were not identified in the cfDNA of any of the nine healthy controls. These results indicate that a fusion gene signature may be readily detectable in glioma patients, thus distinguishing them from non-cancer controls, with high specificity and sensitivity (at 1\% FDR). Furthermore, we analysed our datasets to identify hits among predicted 1207 druggable fusions that had been collected in the ChiTaRS 5.0 database and characterized by a preserved tyrosine kinase domain targeted by chemotherapy drugs. We identified 24 druggable fusions for the crizotinib analogues (i.e. entrectinib and larotrectinib) in tumours of TCGA GBM patients and in gDNA (Fig. 9, Table 4). Particularly, we found two druggable fusion genes in the gDNA of GBM patients \#GB3 and \#GB7 (Table 4), two druggable fusion genes in the cfDNA of GBM patients \#IA and \#VIIIA (Table 4), and one druggable fusion gene in the cfDNA of the healthy control \#TS_0 (Table 4). These results indicate that some glioma patients have druggable biomarkers for the entrectinib or larotrectinib drug (Table 4), which may be used for personalized and improved chemoradiotherapy protocols. However, crizotinib has poor penetration into the CNS and, therefore, is not a good drug candidate for treating brain tumours ${ }^{127,128}$. Therefore, we considered new drugs to treat NTRK and also ROS1 fusions that have shown some brain tumour activities (data are scarce, mainly from brain metastases) like entrectinib and larotrectinib ${ }^{129}$. Regarding ALK inhibitors there are also new drugs with better brain penetration such as lorlatinib ${ }^{130}$ and brigatinib ${ }^{131}$.

Gene enrichment analysis. Since functional mutations and fusions act to disrupt key metabolic pathways in cancer cells, we examined whether glioma-specific pathway disruptions could potentially be treated with targeted drug combinations. First, we found that a specific subset of fusions $(n=5)$ incorporates a druggable oncogene target that is likely to respond to crizotinib analogues i.e. entrectinib and larotrectinib. Furthermore, 15 additional fusions found in 4 glioma patients and 9 glioma samples archived from the TCGA database indicated potential druggability of $38.2 \%$ of all patient samples analysed, via 40 identified genes that are 
frequently involved in gene fusions (Fig. 5,6 \&7). Second, we hypothesized that particular pathways in gliomas were affected by mutations, as well as by fusions. We analysed the gene set and identified pathway enrichment for 96 genes that were previously reported as frequently mutated in glioma patients ${ }^{112,114,123}$. Additionally, we analysed another gene set, which included 40 genes that were frequently observed in fusions in glioma patients. The KEGG PATHWAY database was used for the analysis, and the 10 most significant pathways were identified from each gene set (Fig.10A). The significant pathways for each gene set were then compared between each other. Six significant pathways, namely, the ErbB signaling pathway, the VEGF signaling pathway, the choline metabolism pathway, central carbon metabolism in cancer, the p53 signalling pathway and pathways in non-small cell lung cancer were identified as common between these two gene sets. Such analysis shows that cancer specific pathways are similar and targeted by either acquiring gene mutations or by forming gene fusions. Thus, a comprehensive study of both gene mutations and fusions can contribute to the understanding of targeted pathways in glioma patients.

\section{Discussion}

235 In this study, we showed that cfDNA concentration in the plasma of GBM patients is higher than in low-grade 236 glioma patients, and higher than in healthy persons. The direct association of cfDNA concentration and tDNA 237 burden in plasma was previously reported in a few studies ${ }^{32,45-47}$. Moreover, cfDNA concentration was shown 238 to be a prognostic biomarker in colorectal, ovarian and breast cancers, non-small cell lung cancer (NSCLC) 239 and melanoma cancer ${ }^{64,132-134}$. Therefore, cfDNA concentration can serve as a potential combined biomarker in 240 glioma liquid biopsy, for the diagnosis, prognosis and prediction of glioma tumours. We found that tDNA 241 fragments are continuously circulating in the plasma of GBM patients; this probably reflects the release of 242 more tDNA into the circulation. These findings concur with previous reports ${ }^{135,136}$. The implication is that 243 tumour cfDNA can be used for liquid biopsy tests in GBM patients. We extended these findings by the novel 244 fusions and, particularly, the druggable fusion targets for crizotinib and its new analogues, namely entrectinib 245 and larotrectinib. This demonstrates enhanced CNS penetration in glioma patients, as an alternative line of 246 personalized treatment.

Several studies have reported the dynamics of cfDNA based mutations in patients with various cancers. Early detection of these mutations can be helpful in cancer diagnosis, and in determining treatment response outcome ahead of standard methods. This will contribute to predicting disease state and cancer prognosis ${ }^{64,132-}$ ${ }^{134}$. However, challenges still remain, as distinct diagnostic biomarkers with high sensitivity and specificity have not been identified for most cancer types, including glioma subtypes. In this study, we added to mutation analysis, gene-gene fusions that are known for their tissue specificity, as well as for cancer specificity ${ }^{86,91}$. We describe outcomes of mutation analysis of cfDNA and tDNA in glioma patients, based on previous glioma mutation landscapes. This analysis classifies glioma types and provides information on the genes that were mutated and the pathways affected by the mutations. Mutations in genes such as IDH1/2, TERT, BRAF, EGFR 
and ATRX have been studied for their associations with prognosis and with treatment response ${ }^{11,115-}$ $120,137,138,139,140$.

Particularly, $I D H$ is a major prognostic feature for astrocytomas. Even in tumours that do not show classical histologic features of GBM, $I D H$ wild type status is closely linked to lower overall survival and rapid deterioration $^{141}$. Another important mutation found in our glioma samples is the TERT promoter mutation, which is observed in $70 \%$ of oligodendroglioma and in about $70-80 \%$ of primary GBM. This mutation occurs mainly in the $124 \mathrm{bp}-146 \mathrm{bp}$ upstream of the transcription start site ${ }^{142}$. The TERT promoter mutation has been shown to be a typical feature in progressive $\mathrm{GBM}^{137,138}$. Further, the TERT promoter mutation was found to be associated with shorter overall survival and to be negatively correlated with the grade of astrocytoma ${ }^{11}$. A positive correlation with EGFR amplification and negative correlations with IDHI mutations are key features of TERT promoter mutations in GBM tumours ${ }^{11}$. This suggests that these mutations may be important prognostic markers for patients with glioma. Moreover, we identified a mutation in the ATRX gene that occurs exclusively in astrocytomas ${ }^{139,140}$. Thus, the ATRX mutation is useful in glioma tumour diagnosis, since the presence of both $I D H$ and $A T R X$ mutations is considered a reliable indication of lower grade astrocytomas ${ }^{139,140}$. In contrast, the TERT promoter mutation is seen mainly in primary GBM and oligodendroglioma ${ }^{78,94}$. The BRAF gene encodes the BRAF protein. This serine/threonine kinase serves as an immediate downstream effector of the MAPK signalling cascade, a signal transduction pathway that modulates cell proliferation and survival. BRAF alterations leading to MAPK pathway activation have been identified in gliomas and glio-neuronal tumours of the $\mathrm{CNS}^{124}$. The EGFR mutation is another important gene mutation that we identified. Thus, enhanced activation of EGFR can occur through a variety of mechanisms, both ligand-dependent and ligandindependent ${ }^{125}$. In particular, substantial evidence suggests that $E G F R$ is overexpressed in most primary GBM and in some secondary GBMs, and is characteristic of more aggressive GBM phenotypes ${ }^{125}$. Moreover, we found mutations in a set of genes (i.e., EGFR, IDH1, PDGFRA, PIK3CA, PIK3R1 and TP53) that are involved in the central carbon metabolism pathway in cancer ${ }^{143}$. This pathway helps cancer cells consume a large amount of glucose to maintain a high rate of glycolysis, and provides intermediate molecules to synthesize most of the macromolecules required for the duplication of cancer cell biomass and the genome ${ }^{144}$. Therefore, cfDNA testing may serve as an effective liquid biopsy platform in low- and high-grade gliomas and, particularly, in GBM patients.

We detected the abovementioned mutations in the cfDNA and tDNA of GBM patients. This suggests that liquid biopsy can provide molecular signatures for glioma management. Moreover, these molecular signatures can be monitored serially since liquid biopsy requires only a simple blood test and can be done frequently during the disease course. In 20 TCGA archived GBM patients and 14 of our GBM patients, we found that 20 fusion genes were either formed in large numbers of cfDNA molecules or were rarely

formed. The phenomenon of this activity of fusion genes is still not understood. However, the complete absence of these fusion genes in a healthy control cohort supports the disease specificity of the fusion genes. Next, we 
from the glioma mutation landscape share common pathways that are significant in gliomas. These include the ErbB signaling pathway, the VEGF signaling pathway, the choline metabolism pathway, the central carbon metabolism pathway and the p53 signalling pathway. The ErbB signaling pathway is enriched for both mutations and fusions in gliomas. Receptor proteins ErbB1, ErbB2, ErbB3 and ErbB4 belong to the ErbB receptor family of tyrosine kinases. Upon ligand induction, the receptor activates downstream signaling pathways that lead to cell migration, cell proliferation and anti-apoptosis processes. Mutations in these receptors lead to constitutive activation of receptors, independent of ligand induction. This results in increased cell migration, cell proliferation and anti-apoptosis processes. This alteration is recognized as a key target for alteration in many other tumour types ${ }^{145}$. The VEGF signaling pathway (enriched for both mutations and fusions in gliomas) activates angiogenic protein VEGF under hypoxic conditions and increases vascular permeability. GBM tumours are often hypoxic and require increased angiogenesis. This hypoxia triggers VEGF overexpression, and this contributes to the irregular vasculature associated with $\mathrm{GBM}^{146}$. The choline metabolism pathway was also targeted by mutations and fusions. This pathway is characterized by increased phosphocholine and total choline-containing compounds. Abnormal choline metabolism is influenced by hypoxia conditions in the tumour microenvironment and is found to cause the transformation of non-malignant cells to malignant cells ${ }^{147}$. Thus, gene set enrichment analysis can compare two sets: genes frequently identified as mutated in GBM and genes that were frequently identified as fusions in GBM in the current study. This indicates that fusion genes, together with mutations, directly target the disease-causing pathways in glioma tumours. Therefore, fusion genes can be studied together with mutations for their combined use in estimating precise prognosis and monitoring treatment response by cfDNA in primary brain tumours, and specifically in 312 gliomas.

313 In addition to the role of liquid biopsy in estimating prognosis and treatment response, this technique carries the potential to improve glioma management by providing druggable fusion targets for treating patients. Using liquid biopsy, we identified 15 druggable fusions in four glioma patients. Nine TCGA archived glioma samples indicated potential druggability of $38.2 \%$ of all the patient samples analysed. In three GBM patients, 317 we identified $A L K$-based druggable fusions, namely $T F G-A L K, M S N-A L K$ and $N P M 1-A L K$. In a previous study, 318 NSCLC patients with $A L K$-positive fusions were treated with the kinase inhibitor crizotinib for a mean duration 319 of 6.4 months. The overall response rate was $57 \%$ (47 of 82 patients: 46 confirmed partial responses and 1 confirmed complete response); 27 patients $(33 \%)$ had stable disease ${ }^{96,148}$. Two additional important druggable fusions that we found in two GBM patients were SDC4-ROS1 and TPM3-ROS1. ROS1-based fusions were initially discovered in the human glioblastoma cell line $\mathrm{U} 118 \mathrm{MG}^{149,150}$. A previous in-vitro study showed that treatment with ROS1 inhibitor crizotinib was anti-proliferative and that it downregulated signalling pathways that are critical for growth and survival ${ }^{151}$. We detected $B C R$-ABL1 fusions in two, NIN-PDGFRB in three and COL1A1-PDGFB in one of our GBM patients. These three fusion genes can be targeted by the common drug imatinib (Gleevec) ${ }^{152,153,154}$. Therefore, targeted drugs with improved brain penetration should be tested, based on the dynamics of fusions detected in patients' plasma. 
In conclusion, we showed that liquid biopsy may have an important role in glioma management. This is

due to its non-invasive nature and its ability to provide broad range information on real-time activity of mutations and gene fusions in brain tumour patients. Specific gene mutations and fusion genes can act as combined markers for estimating prognosis and treatment outcomes in these patients. Therapeutic druggable fusion gene targets can be identified using liquid biopsy; this will contribute to precise treatment of glioma patients using non-invasive liquid biopsy diagnostic technique.

\section{References}

1. Barnholtz-Sloan, J. S., Ostrom, Q. T. \& Cote, D. Epidemiology of Brain Tumors. Neurol. Clin. 36, 395419 (2018).

2. Goodenberger, M. L. \& Jenkins, R. B. Genetics of adult glioma. Cancer Genet. 205, 613-621 (2012).

3. Ahmed, R., Oborski, M. J., Hwang, M., Lieberman, F. S. \& Mountz, J. M. Malignant gliomas: current perspectives in diagnosis, treatment, and early response assessment using advanced quantitative imaging methods. Cancer Manag. Res. 6, 149-70 (2014).

4. Posti, J. P. et al. Presenting symptoms of glioma in adults. Acta Neurol. Scand. 131, 88-93 (2015).

5. Mondal, A., Kumari Singh, D., Panda, S. \& Shiras, A. Extracellular Vesicles As Modulators of Tumor Microenvironment and Disease Progression in Glioma. Front. Oncol. 7, 144 (2017).

6. Shergalis, A., Bankhead, A., Luesakul, U., Muangsin, N. \& Neamati, N. Current Challenges and Opportunities in Treating Glioblastoma. Pharmacol. Rev. 70, 412-445 (2018).

7. Diwanji, T. P., Engelman, A., Snider, J. W. \& Mohindra, P. Epidemiology, diagnosis, and optimal management of glioma in adolescents and young adults. Adolesc. Health. Med. Ther. 8, 99-113 (2017).

8. Dhermain, F. Radiotherapy of high-grade gliomas: current standards and new concepts, innovations in imaging and radiotherapy, and new therapeutic approaches. Chin. J. Cancer 33, 16-24 (2014).

9. Ghotme, K. A. et al. Gliomas: New Perspectives in Diagnosis, Treatment and Prognosis. Curr. Top. Med. Chem. (2017).

10. Stummer, W. et al. Fluorescence-guided surgery with 5-aminolevulinic acid for resection of malignant glioma: a randomised controlled multicentre phase III trial. Lancet Oncol. 7, 392-401 (2006).

11. Simon, M. et al. TERT promoter mutations: a novel independent prognostic factor in primary glioblastomas. Neuro. Oncol. 17, 45-52 (2015).

12. Saenz-Antoñanzas, A. et al. Liquid Biopsy in Glioblastoma: Opportunities, Applications and Challenges. Cancers (Basel). 11, (2019).

13. G Siravegna, S. M. S. S. A. B., Siravegna, G., Marsoni, S., Siena, S. \& Bardelli, A. Integrating liquid biopsies into the management of cancer. 14, 531-548 (2017).

14. Friedmann-Morvinski, D. Glioblastoma Heterogeneity and Cancer Cell Plasticity. Crit. Rev. Oncog. 19, 327-336 (2014).

15. Abi-Aad, K. R., Acis, O., Welz, M. E. \& Bendok, B. R. Glioma “Liquid Biopsy”: A New Frontier in Neurosurgery. Neurosurgery 85, E203-E204 (2019).

16. Bagley, S. et al. Clinical utility of plasma cell-free DNA in adult patients with newly diagnosed glioblastoma - a pilot prospective study. Clin. Cancer Res. clincanres.2533.2019 (2019) doi:10.1158/1078-0432.CCR-19-2533.

17. Crowley, E., Di Nicolantonio, F., Loupakis, F. \& Bardelli, A. Liquid biopsy: monitoring cancer-genetics in the blood. Nat. Rev. Clin. Oncol. 10, 472-484 (2013).

18. Pantel, K. \& Alix-Panabières, C. Liquid biopsy and minimal residual disease — latest advances and implications for cure. Nat. Rev. Clin. Oncol. 16, 409-424 (2019).

19. Mattox, A. K. et al. Applications of liquid biopsies for cancer. Sci. Transl. Med. 11, eaay1984 (2019).

20. Merker, J. Circulating tumor DNA analysis in patients with cancer: American Society of Clinical Oncology and College of American Pathologists Joint Review. J. Clin. Oncol. 36, 1631-1641 (2018).

21. Heitzer, E., Ulz, P. \& Geigl, J. B. Circulating Tumor DNA as a Liquid Biopsy for Cancer. Clin. Chem. 61, 112-123 (2015).

22. Pantel, K. \& Alix-Panabières, C. Liquid biopsy in 2016: Circulating tumour cells and cell-free DNA in gastrointestinal cancer. Nat. Rev. Gastroenterol. Hepatol. 2017142 (2017). 
23. Sorber, L. et al. Circulating Cell-Free DNA and RNA Analysis as Liquid Biopsy: Optimal

Centrifugation Protocol. Cancers (Basel). 11, 458 (2019).

24. Hodara, E. et al. Multi-parametric liquid biopsy analysis of circulating tumor cells (CTCs), cell-free DNA (cfDNA), and cell-free RNA (cfRNA) in metastatic castrate resistant prostate cancer (mCRPC). $J$. Clin. Oncol. 36, 274-274 (2018).

25. Ilié, M. \& Hofman, P. Pros: Can tissue biopsy be replaced by liquid biopsy? Transl. lung cancer Res. 5, 420-3 (2016).

26. El-Hefnawy, T. et al. Characterization of amplifiable, circulating RNA in plasma and its potential as a tool for cancer diagnostics. Clin. Chem. 50, 564-73 (2004).

27. KOPRESKI, M. S., BENKO, F. A. \& GOCKE, C. D. Circulating RNA as a Tumor Marker. Ann. N. Y. Acad. Sci. 945, 172-178 (2006).

28. FENG, G., LI, G., GENTIL-PERRET, A., TOSTAIN, J. \& GENIN, C. Anticancer research. Anticancer Research vol. 28 ([Potamitis Press], 1981).

29. Zhao, Z. et al. Extracellular vesicles as cancer liquid biopsies: from discovery, validation, to clinical application. Lab Chip 19, 1114-1140 (2019).

30. Armstrong, D. \& Wildman, D. E. Extracellular Vesicles and the Promise of Continuous Liquid Biopsies. J. Pathol. Transl. Med. 52, 1-8 (2018).

31. Kosaka, N. et al. Exploiting the message from cancer: the diagnostic value of extracellular vesicles for clinical applications. Exp. Mol. Med. 51, 31 (2019).

32. Marrugo-Ramírez, J., Mir, M. \& Samitier, J. Blood-Based Cancer Biomarkers in Liquid Biopsy: A Promising Non-Invasive Alternative to Tissue Biopsy. Int. J. Mol. Sci. 19, (2018).

33. Lianidou, E. \& Pantel, K. Liquid biopsies. Genes, Chromosom. Cancer 58, 219-232 (2019).

34. Trapp, E. et al. Presence of Circulating Tumor Cells in High-Risk Early Breast Cancer During FollowUp and Prognosis. JNCI J. Natl. Cancer Inst. 111, 380-387 (2019).

35. Brody, T. \& Brody, T. Biomarkers. Clin. Trials 377-419 (2016) doi:10.1016/B978-0-12-8042175.00019-9.

36. Schettini, F., Giuliano, M. \& Cristofanilli, M. Prognostic and Predictive Role of Circulating Tumor Cells. Oncogenomics 181-190 (2019) doi:10.1016/B978-0-12-811785-9.00012-0.

37. Sundling, K. E. \& Lowe, A. C. Circulating Tumor Cells. Adv. Anat. Pathol. 1 (2018) doi:10.1097/PAP.0000000000000217.

38. Krebs, M. G., Hou, J.-M., Ward, T. H., Blackhall, F. H. \& Dive, C. Circulating tumour cells: their utility in cancer management and predicting outcomes. Ther. Adv. Med. Oncol. 2, 351-65 (2010).

39. Ribeiro-Samy, S. et al. Fast and efficient microfluidic cell filter for isolation of circulating tumor cells from unprocessed whole blood of colorectal cancer patients. Sci. Rep. 9, 8032 (2019).

40. Guo, H. et al. Direct Detection of Circulating Tumor Cells in Whole Blood Using Time-Resolved Luminescent Lanthanide Nanoprobes. Angew. Chemie Int. Ed. 58, 12195-12199 (2019).

41. Palmirotta, R. et al. Liquid biopsy of cancer: a multimodal diagnostic tool in clinical oncology. Ther. Adv. Med. Oncol. 10, 175883591879463 (2018).

42. Elazezy, M. \& Joosse, S. A. Techniques of using circulating tumor DNA as a liquid biopsy component in cancer management. Comput. Struct. Biotechnol. J. 16, 370-378 (2018).

43. Shankar, G. M. et al. Liquid biopsy for brain tumors. Expert Rev. Mol. Diagn. 17, 943-947 (2017).

44. Wang, W. et al. Characterization of the release and biological significance of cell-free DNA from breast cancer cell lines. Oncotarget 8, 43180-43191 (2017).

45. Spindler, K.-L. G. et al. Cell-free DNA in healthy individuals, noncancerous disease and strong prognostic value in colorectal cancer. Int. J. Cancer 135, 2984-2991 (2014).

46. Jung, K., Fleischhacker, M. \& Rabien, A. Cell-free DNA in the blood as a solid tumor biomarker-A critical appraisal of the literature. Clin. Chim. Acta 411, 1611-1624 (2010).

47. Yu, D. et al. Diagnostic Value of Concentration of Circulating Cell-Free DNA in Breast Cancer: A Meta-Analysis. Front. Oncol. 9, 95 (2019).

48. Vlassov, V. V., Laktionov, P. P. \& Rykova, E. Y. Extracellular nucleic acids. BioEssays 29, 654-667 (2007).

49. Jahr, S. et al. DNA fragments in the blood plasma of cancer patients: quantitations and evidence for their origin from apoptotic and necrotic cells. Cancer Res. 61, 1659-65 (2001).

50. Rykova, E. Y. et al. Cell-free and cell-bound circulating nucleic acid complexes: mechanisms of generation, concentration and content. Expert Opin. Biol. Ther. 12, S141-S153 (2012). 
51. Snyder, M. W., Kircher, M., Hill, A. J., Daza, R. M. \& Shendure, J. Cell-free DNA Comprises an In Vivo Nucleosome Footprint that Informs Its Tissues-Of-Origin. Cell 164, 57-68 (2016).

52. Agostini, M. et al. Circulating cell-free DNA: A promising marker of regional lymphonode metastasis in breast cancer patients. Cancer Biomarkers 11, 89-98 (2012).

53. Vymetalkova, V., Cervena, K., Bartu, L. \& Vodicka, P. Circulating Cell-Free DNA and Colorectal Cancer: A Systematic Review. Int. J. Mol. Sci. 19, (2018).

54. Connolly, I. D., Li, Y., Gephart, M. H. \& Nagpal, S. The 'Liquid Biopsy': the Role of Circulating DNA and RNA in Central Nervous System Tumors. Curr Neurol Neurosci Rep 16, 25 (2016).

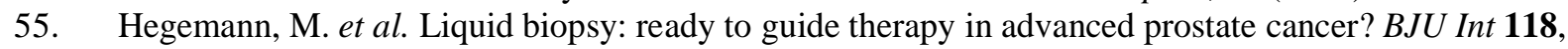
$855-863$ (2016).

56. Imamura, T. et al. Liquid biopsy in patients with pancreatic cancer: Circulating tumor cells and cell-free nucleic acids. World J Gastroenterol 22, 5627-5641 (2016).

57. Mansour, H. Cell-free nucleic acids as noninvasive biomarkers for colorectal cancer detection. Front Genet 5, 182 (2014).

58. Okajima, W. et al. Liquid biopsy in patients with hepatocellular carcinoma: Circulating tumor cells and cell-free nucleic acids. World J Gastroenterol 23, 5650-5668 (2017).

59. Rapisuwon, S., Vietsch, E. E. \& Wellstein, A. Circulating biomarkers to monitor cancer progression and treatment. Comput Struct Biotechnol J 14, 211-222 (2016).

60. Schwarzenbach, H., Müller, V., Milde-Langosch, K., Steinbach, B. \& Pantel, K. Evaluation of cell-free tumour DNA and RNA in patients with breast cancer and benign breast disease. Mol. Biosyst. 7, 2848 (2011).

61. Murtaza, M. et al. Multifocal clonal evolution characterized using circulating tumour DNA in a case of metastatic breast cancer. Nat Commun 6, 8760 (2015).

62. Lawrence, M. S. et al. Mutational heterogeneity in cancer and the search for new cancer-associated genes. Nature 499, 214-218 (2013).

63. Murtaza, M. et al. Non-invasive analysis of acquired resistance to cancer therapy by sequencing of plasma DNA. Nature 497, 108-112 (2013).

64. Bedin, C. et al. Diagnostic and prognostic role of cell-free DNA testing for colorectal cancer patients. Int J Cancer 140, 1888-1898 (2017).

65. Dahlstrom, K. R. et al. Circulating human papillomavirus DNA as a marker for disease extent and recurrence among patients with oropharyngeal cancer. Cancer 121, 3455-3464 (2015).

66. Madhavan, D. et al. Plasma DNA integrity as a biomarker for primary and metastatic breast cancer and potential marker for early diagnosis. Breast Cancer Res Treat 146, 163-174 (2014).

67. Nawroz-Danish, H. et al. Microsatellite analysis of serum DNA in patients with head and neck cancer. Int J Cancer 111, 96-100 (2004).

68. Yip, T. T., Ngan, R. K., Fong, A. H. \& Law, S. C. Application of circulating plasma/serum EBV DNA in the clinical management of nasopharyngeal carcinoma. Oral Oncol 50, 527-538 (2014).

69. Bettegowda, C. et al. Detection of circulating tumor DNA in early- and late-stage human malignancies. Sci. Transl. Med. 6, 224ra24 (2014).

70. Bonner, E. R., Bornhorst, M., Packer, R. J. \& Nazarian, J. Liquid biopsy for pediatric central nervous system tumors. NPJ Precis. Oncol. 2, 29 (2018).

71. Louis, D. N. et al. The 2016 World Health Organization Classification of Tumors of the Central Nervous System: a summary. Acta Neuropathol. 131, 803-820 (2016).

72. Beaver, J. A. et al. Detection of cancer DNA in plasma of patients with early-stage breast cancer. Clin Cancer Res 20, 2643-2650 (2014).

73. Komori, T. The 2016 WHO Classification of Tumours of the Central Nervous System: The Major Points of Revision. Neurol. Med. Chir. (Tokyo). 57, 301-311 (2017).

74. Johnson, D. R. et al. 2016 Updates to the WHO Brain Tumor Classification System: What the Radiologist Needs to Know. RadioGraphics 37, 2164-2180 (2017).

75. Di Carlo, D. T. et al. IDH wild-type WHO grade II diffuse low-grade gliomas. A heterogeneous family with different outcomes. Systematic review and meta-analysis. Neurosurg. Rev. (2018) doi:10.1007/s10143-018-0996-3.

76. Louis, D. N. et al. cIMPACT-NOW update 2: diagnostic clarifications for diffuse midline glioma, H3 K27M-mutant and diffuse astrocytoma/anaplastic astrocytoma, IDH-mutant. Acta Neuropathol. 135, 639-642 (2018). 
77. Kondo, T. Molecular mechanisms involved in gliomagenesis. Brain Tumor Pathol. 1-7 (2017) doi:10.1007/s10014-017-0278-8.

78. Siegal, T. Clinical impact of molecular biomarkers in gliomas. J. Clin. Neurosci. 22, 437-444 (2015).

79. Lin, A. J. et al. Oligodendroglioma Patients with $1 \mathrm{p} / 19 \mathrm{q}$ Co-deletion Treated with Early or Delayed Radiation Therapy over the Last Two Decades: A Multi-institutional Report. Int. J. Radiat. Oncol. 102, e282-e283 (2018).

80. Chen, H. et al. Polysomy is associated with poor outcome in $1 \mathrm{p} / 19 \mathrm{q}$ codeleted oligodendroglial tumors. Neuro. Oncol. 21, 1164-1174 (2019).

81. Ishida, A. et al. Papillary tumor of the pineal region: a case involving isocitrate dehydrogenase (IDH) genotyping. Brain Tumor Pathol. 30, 45-49 (2013).

82. Polivka, J. et al. Co-deletion of $1 \mathrm{p} / 19 \mathrm{q}$ as Prognostic and Predictive Biomarker for Patients in West Bohemia with Anaplastic Oligodendroglioma. Anticancer Res. 36, 471-6 (2016).

83. $\mathrm{Hu}$, X. et al. Multigene signature for predicting prognosis of patients with $1 \mathrm{p} 19 \mathrm{q}$ co-deletion diffuse glioma. Neuro. Oncol. 19, 786-795 (2017).

84. Frenel, J. S. et al. Combining two biomarkers, IDH1/2 mutations and 1p/19q codeletion, to stratify anaplastic oligodendroglioma in three groups: a single-center experience. J. Neurooncol. 114, 85-91 (2013).

85. Parker, B. C. \& Zhang, W. Fusion genes in solid tumors: an emerging target for cancer diagnosis and treatment. Chin. J. Cancer 32, 594-603 (2013).

86. Yu, Y.-P. et al. Identification of recurrent fusion genes across multiple cancer types. Sci. Rep. 9, 1074 (2019).

87. Parker, M. et al. C11 orf95-RELA fusions drive oncogenic NF-kB signalling in ependymoma. Nature 506, 451-455 (2014).

88. Gao, Q. et al. Driver Fusions and Their Implications in the Development and Treatment of Human Cancers. Cell Rep. 23, 227-238.e3 (2018).

89. Perner, S. et al. TMPRSS2:ERG Fusion-Associated Deletions Provide Insight into the Heterogeneity of Prostate Cancer. Cancer Res. 66, 8337-8341 (2006).

90. Soller, M. J. et al. Confirmation of the high frequency of theTMPRSS2/ERG fusion gene in prostate cancer. Genes, Chromosom. Cancer 45, 717-719 (2006).

91. Tomlins, S. A. et al. Recurrent Fusion of TMPRSS2 and ETS Transcription Factor Genes in Prostate Cancer. Science (80-. ). 310, (2005).

92. Salesse, S. \& Verfaillie, C. M. BCR/ABL: from molecular mechanisms of leukemia induction to treatment of chronic myelogenous leukemia. Oncogene 21, 8547-8559 (2002).

93. International Cancer Genome Consortium PedBrain Tumor Project. Recurrent MET fusion genes represent a drug target in pediatric glioblastoma. Nat. Med. 22, 1314-1320 (2016).

94. Wu, G. et al. The genomic landscape of diffuse intrinsic pontine glioma and pediatric non-brainstem high-grade glioma. Nat. Genet. 46, 444-450 (2014).

95. Lobato, M. N. et al. Modeling chromosomal translocations using conditional alleles to recapitulate initiating events in human leukemias. J. Natl. Cancer Inst. - Monogr. 2008, 58-63 (2008).

96. Soda, M. et al. Identification of the transforming EML4-ALK fusion gene in non-small-cell lung cancer. Nature 448, 561-566 (2007).

97. Strain, M. C. et al. Highly Precise Measurement of HIV DNA by Droplet Digital PCR. PLoS One 8, e55943 (2013).

98. Zhu, Z. et al. Highly sensitive and quantitative detection of rare pathogens through agarose droplet microfluidic emulsion PCR at the single-cell level. Lab Chip 12, 3907 (2012).

99. Zonta, E. et al. Multiplex Detection of Rare Mutations by Picoliter Droplet Based Digital PCR: Sensitivity and Specificity Considerations. PLoS One 11, e0159094 (2016).

100. Li, H. et al. Application of droplet digital PCR to detect the pathogens of infectious diseases. Biosci. Rep. 38, (2018).

101. Dong, L., Wang, S., Fu, B. \& Wang, J. Evaluation of droplet digital PCR and next generation sequencing for characterizing DNA reference material for KRAS mutation detection. Sci. Reports 201881 8, 1-9 (2018).

102. Miotke, L., Lau, B. T., Rumma, R. T. \& Ji, H. P. High Sensitivity Detection and Quantitation of DNA Copy Number and Single Nucleotide Variants with Single Color Droplet Digital PCR. Anal. Chem. 86, 2618-2624 (2014). 
103. Quan, P.-L., Sauzade, M. \& Brouzes, E. dPCR: A Technology Review. Sensors (Basel). 18, (2018).

104. Jennings, L. J., George, D., Czech, J., Yu, M. \& Joseph, L. Detection and Quantification of BCR-ABL1 Fusion Transcripts by Droplet Digital PCR. J. Mol. Diagnostics 16, 174-179 (2014).

105. Krumbholz, M. et al. Large amplicon droplet digital PCR for DNA $\square$ based monitoring of pediatric chronic myeloid leukaemia. J. Cell. Mol. Med. 23, 4955-4961 (2019).

106. Zhou, R. et al. A digital PCR based assay to detect all ALK fusion species. Front. Lab. Med. 2, 49-54 (2018).

107. Wang, Q. et al. Droplet Digital PCR for Absolute Quantification of EML4-ALK Gene Rearrangement in Lung Adenocarcinoma. J. Mol. Diagnostics 17, 515-520 (2015).

108. Gorohovski, A. et al. ChiTaRS-3.1-the enhanced chimeric transcripts and RNA-seq database matched with protein-protein interactions. Nucleic Acids Res 45, D790-D795 (2017).

109. Frenkel-Morgenstern, M., Gorohovski, A., Vucenovic, D., Maestre, L. \& Valencia, A. ChiTaRS 2.1-an improved database of the chimeric transcripts and RNA-seq data with novel sense-antisense chimeric RNA transcripts. Nucleic Acids Res (2014) doi:10.1093/nar/gku1199.

110. Gorohovski, A. et al. ChiTaRS-3.1 - the enhanced chimeric transcripts and RNA-seq database matched with protein-protein interactions. Nucleic Acids Res. 45, D790--D795 (2017).

111. Mouliere, F., El Messaoudi, S., Pang, D., Dritschilo, A. \& Thierry, A. R. Multi-marker analysis of circulating cell-free DNA toward personalized medicine for colorectal cancer. Mol. Oncol. 8, 927-941 (2014).

112. Piccioni, D. E. et al. Analysis of cell-free circulating tumor DNA in 419 patients with glioblastoma and other primary brain tumors. CNS Oncol. 8, CNS34 (2019).

113. Gao, J. et al. Integrative analysis of complex cancer genomics and clinical profiles using the cBioPortal. Sci. Signal. 6, (2013).

114. Tate, J. G. et al. COSMIC: the Catalogue Of Somatic Mutations In Cancer. Nucleic Acids Res. 47, D941-D947 (2019).

115. Yan, H. et al. IDH1 and IDH2 Mutations in Gliomas. N. Engl. J. Med. 360, 765-773 (2009).

116. Ichimura, K. Molecular pathogenesis of IDH mutations in gliomas. Brain Tumor Pathol. 29, 131-139 (2012).

117. Yen, K. E., Bittinger, M. A., Su, S. M. \& Fantin, V. R. Cancer-associated IDH mutations: biomarker and therapeutic opportunities. Oncogene 29, 6409-6417 (2010).

118. Kim, W. \& Liau, L. M. IDH mutations in human glioma. Neurosurg. Clin. N. Am. 23, 471-80 (2012).

119. Dang, L., Jin, S. \& Su, S. M. IDH mutations in glioma and acute myeloid leukemia. Trends Mol. Med. 16, 387-397 (2010).

120. Cohen, A. L., Holmen, S. L. \& Colman, H. IDH1 and IDH2 Mutations in Gliomas. Curr. Neurol. Neurosci. Rep. 13, 345 (2013).

121. Guo, C., Pirozzi, C. J., Lopez, G. Y. \& Yan, H. Isocitrate dehydrogenase mutations in gliomas: mechanisms, biomarkers and therapeutic target. Curr. Opin. Neurol. 24, 648 (2011).

122. Waitkus, M. S., Diplas, B. H. \& Yan, H. Isocitrate dehydrogenase mutations in gliomas. Neuro. Oncol. 18, 16-26 (2016).

123. Brennan, C. W. et al. The somatic genomic landscape of glioblastoma. Cell 155, 462 (2013).

124. Kuroda, J. I. et al. A case of an epithelioid glioblastoma with the BRAF V600E mutation colocalized with BRAF intact low-grade diffuse astrocytoma. Neuropathology 36, 181-186 (2016).

125. Xu, H. et al. Epidermal growth factor receptor in glioblastoma (Review). Oncol. Lett. 14, 512-516 (2017).

126. Balamurali, D. et al. ChiTaRS 5.0: the comprehensive database of chimeric transcripts matched with druggable fusions and 3D chromatin maps. Nucleic Acids Res. (2019) doi:10.1093/nar/gkz1025.

127. Costa, D. B. et al. CSF concentration of the anaplastic lymphoma kinase inhibitor crizotinib. J. Clin. Oncol. 29, (2011).

128. Yoshida, T. et al. Clinical impact of crizotinib on central nervous system progression in ALK-positive non-small lung cancer. Lung Cancer 97, 43-47 (2016).

129. Drilon, A. et al. Safety and antitumor activity of the multitargeted pan-TRK, ROS1, and ALK inhibitor entrectinib: Combined results from two phase I trials (ALKA-372-001 and STARTRK-1). Cancer Discov. 7, 400-409 (2017).

130. Akamine, T., Toyokawa, G., Tagawa, T. \& Seto, T. Spotlight on lorlatinib and its potential in the treatment of NSCLC: The evidence to date. OncoTargets and Therapy vol. 11 5093-5101 (2018). 
131. Zweig, J. R. \& Neal, J. W. Infiltrating the Blood-Brain Barrier in ALK-Positive Lung Cancer. J. Clin. Oncol. 36, 2677-2679 (2018).

132. Steffensen, K. D. et al. Prognostic importance of cell-free DNA in chemotherapy resistant ovarian cancer treated with bevacizumab. Eur. J. Cancer 50, 2611-2618 (2014).

133. Shaw, J. A. et al. Genomic analysis of circulating cell-free DNA infers breast cancer dormancy. Genome Res. 22, 220-231 (2012).

134. Prez-Callejo, D. et al. Liquid biopsy based biomarkers in non-small cell lung cancer for diagnosis and treatment monitoring. Transl. lung cancer Res. 5, 455-465 (2016).

135. Deeken, J. F. \& Löscher, W. The blood-brain barrier and cancer: Transporters, treatment, and trojan horses. Clinical Cancer Research vol. 13 1663-1674 (2007).

136. Tyler, B. M. et al. Peptide nucleic acids targeted to the neurotensin receptor and administered i.p. cross the blood-brain barrier and specifically reduce gene expression. Proc. Natl. Acad. Sci. U. S. A. 96, 70537058 (1999).

137. Tabori, U. et al. Human Telomere Reverse Transcriptase Expression Predicts Progression and Survival in Pediatric Intracranial Ependymoma. J. Clin. Oncol. 24, 1522-1528 (2006).

138. Eckel-Passow, J. E. et al. Glioma Groups Based on 1p/19q, IDH , and TERT Promoter Mutations in Tumors. N. Engl. J. Med. 372, 2499-2508 (2015).

139. Jiao, Y. et al. Frequent ATRX, CIC, FUBP1 and IDH1 mutations refine the classification of malignant gliomas. Oncotarget 3, (2012).

140. Killela, P. J. et al. TERT promoter mutations occur frequently in gliomas and a subset of tumors derived from cells with low rates of self-renewal. Proc. Natl. Acad. Sci. 110, 6021-6026 (2013).

141. Louis, D. N. et al. The 2016 World Health Organization Classification of Tumors of the Central Nervous System: a summary. Acta Neuropathol. 131, 803-820 (2016).

142. Spiegl-Kreinecker, S. et al. Prognostic quality of activating TERT promoter mutations in glioblastoma: interaction with the rs 2853669 polymorphism and patient age at diagnosis. Neuro. Oncol. 17, 1231-1240 (2015).

143. Guarente, L. The many faces of sirtuins: Sirtuins and the warburg effect. Nat. Med. 20, 24-25 (2014).

144. Chen, J. Q. \& Russo, J. Dysregulation of glucose transport, glycolysis, TCA cycle and glutaminolysis by oncogenes and tumor suppressors in cancer cells. Biochimica et Biophysica Acta - Reviews on Cancer vol. 1826 370-384 (2012).

145. Berezowska, S. \& Schlegel, J. Targeting ErbB Receptors in High-Grade Glioma. Curr. Pharm. Des. 17, 2468-2487 (2011).

146. Pearson, J. R. D. \& Regad, T. Targeting cellular pathways in glioblastoma multiforme. Signal Transduction and Targeted Therapy vol. 2 (2017).

147. Glunde, K., Bhujwalla, Z. M. \& Ronen, S. M. Choline metabolism in malignant transformation. Nature Reviews Cancer vol. 11 835-848 (2011).

148. Kwak, E. L. et al. Anaplastic lymphoma kinase inhibition in non-small-cell lung cancer. N. Engl. J. Med. 363, 1693-1703 (2010).

149. Birchmeier, C., Sharma, S. \& Wigler, M. Expression and rearrangement of the ROS1 gene in human glioblastoma cells. Proc. Natl. Acad. Sci. U. S. A. 84, 9270-9274 (1987).

150. Charest, A. et al. Fusion of FIG to the receptor tyrosine kinase ROS in a glioblastoma with an interstitial del(6)(q21q21). Genes Chromosom. Cancer 37, 58-71 (2003).

151. Davies, K. D. et al. Identifying and targeting ROS1 gene fusions in non-small cell lung cancer. Clin. Cancer Res. 18, 4570-4579 (2012).

152. Rossari, F., Minutolo, F. \& Orciuolo, E. Past, present, and future of Bcr-Abl inhibitors: From chemical development to clinical efficacy. Journal of Hematology and Oncology vol. 11 (2018).

153. Kindler, T., Meyer, R. G. \& Fischer, T. BCR-ABL as a target for novel therapeutic interventions. Expert Opinion on Therapeutic Targets vol. 6 85-101 (2002).

154. Cheah, C. Y. et al. Patients with myeloid malignancies bearing PDGFRB fusion genes achieve durable long-term remissions with imatinib. Blood 123, 3574-3577 (2014).

155. Martin, M. Cutadapt removes adapter sequences from high-throughput sequencing reads. EMBnet.journal 17, 10 (2011).

156. Langmead, B. \& Salzberg, S. L. Fast gapped-read alignment with Bowtie 2. Nat. Methods 9, 357-359 (2012).

157. Li, H. et al. The Sequence Alignment/Map format and SAMtools. Bioinformatics 25, 2078-2079 (2009). 
654

655

656

657

658

659

660

661

662

663

664

665

666

667

668

669
158. Narasimhan, V. et al. BCFtools/RoH: a hidden Markov model approach for detecting autozygosity from next-generation sequencing data. Bioinformatics 32, 1749-51 (2016).

159. McLaren, W. et al. The Ensembl Variant Effect Predictor. Genome Biol. 17, (2016).

160. Liao, Y., Wang, J., Jaehnig, E. J., Shi, Z. \& Zhang, B. WebGestalt 2019: gene set analysis toolkit with revamped UIs and APIs. Nucleic Acids Res. 47, W199-W205 (2019).

161. Kanehisa, M. Toward understanding the origin and evolution of cellular organisms. Protein Sci. (2019) doi:10.1002/pro.3715.

162. Kanehisa, M., Sato, Y., Furumichi, M., Morishima, K. \& Tanabe, M. New approach for understanding genome variations in KEGG. Nucleic Acids Res. 47, D590-D595 (2019).

163. Untergasser, A. et al. Primer3--new capabilities and interfaces. Nucleic Acids Res. 40, e115-e115 (2012).

164. Johnson, M. et al. NCBI BLAST: a better web interface. Nucleic Acids Res. 36, (2008).

165. Chromas and ChromasPro DNA Sequencing Software - Technelysium Pty Ltd. http://technelysium.com.au/wp/. 
671 Sample collection, storage and maintenance. From 27 glioma patients, brain tumour samples (fresh frozen),

672 blood plasma and peripheral blood mononuclear cells (PBMCs) were obtained from several hospitals and from

673 a biorepository. Three samples were provided by Prof. Rainer Glaß, the Department of Neurosurgery, Ludwig-

674 Maximilians-University, Munich, Germany; 9 samples were provided by Dr. Charlotte Flueh, the Department of

675 Neurosurgery, University Hospital of Schleswig-Holstein, Campus Kiel, Kiel, Germany, 10 samples were

676 provided by Prof. Tali Siegal, Neuro-Oncology Center, Rabin Medical Center, Petach Tikva, Israel, and 5

677 samples were provided by The Israeli Biorepository Network for Research (MIDGAM). From 14 healthy

678 controls, we collected blood samples that were separated into plasma and PBMCs. Blood was collected into

679 EDTA-anticoagulated tubes, and plasma was separated within 2 hours of collection. About 1-2 ml of plasma

680 and about $1 \mathrm{ml}$ of PBMC were separated from each blood sample. Both samples were kept at $-80^{\circ} \mathrm{C}$ and were

681 shipped on dry ice.

682

683 DNA isolation. Cell-free DNA (cfDNA) was isolated using QIAamp Circulating Nucleic Acid Kit (Qiagen ${ }^{\circledR}$,

684 Germany) from different volumes of plasma samples ( $850 \mu 1$ to $2 \mathrm{ml}$ ), and from $5 \mathrm{ml}$ culture media collected from

685 glioblastoma cell line cultures. All samples were processed according to the manufacturer's standard protocol.

686 NucleoSpin ${ }^{\circledR}$ Tissue kit (Macherey-Nagel, Germany) was used to process genomic DNA from 25 mg of brain 687 tumour biopsies and from $0.5 \mathrm{ml}$ of PBMC samples from each patient. Isolated DNA samples were stored at $68820^{\circ} \mathrm{C}$ until further use.

689

690 Nucleosomal DNA isolation. Nucleosomal DNA was isolated from the glioblastoma cell line LN-229 and 691 astrocytoma grade-IV cell line CCF-STTG1 using ACTIVE MOTIF ${ }^{\circledR}$ Nucleosome Preparation Kit ${ }^{\mathrm{TM}}$. Isolated 692 DNA samples were then stored at $-20^{\circ} \mathrm{C}$ until their further use.

DNA quantification. All isolated DNA samples were quantified by Qubit ${ }^{\circledR}$ dsDNA HS assay using Qubit ${ }^{\circledR} 2.0$ fluorometer. The assay was performed according to the manufacturer's standard protocol. Fluorescence was measured at 485/530 nm on a Qubit ${ }^{\circledR} 2.0$ fluorometer to determine DNA concentration for each sample. A Bioanalyzer 2100 DNA High Sensitivity assay was performed to estimate the fragment size distribution of isolated cfDNA samples. for NGS library preparation and sample libraries were sequenced on Illumina HiSeq 2500 and Illumina NextSeq 550 platforms. The covaris fragmentation step was performed only for tDNA and germline DNA from PBMCs, and not for cfDNA.

NGS libraries were prepared for cfDNA, tDNA and germline DNA (PBMC) samples, and were 
patients were sequenced as whole genome sequencing at an average of 5x coverage (cfDNA and tDNA) and whole exome sequencing at an average of $180 \mathrm{X}$ coverage (for germline DNA).

NGS data were subject to quality control analysis of raw sequencing reads using FastQC and an additional in-house shell script. Adapters and low-quality sequences were trimmed using Cutadapt tool ${ }^{155}$. Remaining reads were mapped to a human genome reference (hg38) using Bowtie $2^{156}$ and SAMtools ${ }^{157}$. Next, SNVs were identified using bcftools ${ }^{158}$ mpileup for each sample. Further, germline variants identified in PBMC DNA were removed from respective patients' tumours and cfDNA variants, and considered as somatic variants. Somatic variants from cfDNA and tDNA were annotated using standalone Ensembl Variant Effect Predictor (VEP) pipeline ${ }^{159}$.

Reads unmapped to the reference human genome (hg38) were extracted using SAMtools ${ }^{157}$. These were mapped against the reference database of unique chimera junction sequences, ChiTaRS-3.1 ${ }^{110}$, using an inhouse chimera algorithm.

Gene set enrichment analysis. Gene set enrichment analysis was performed using the online tool 'webgestalt ${ }^{160}$, in which two gene sets (i.e., a set of genes commonly mutated in GBM and a set of genes that fused with high frequencies in GBM tumours and cfDNA) are analyzed against the KEGG PATHWAY ${ }^{161,162}$ database. The aim is identification of the 100 most significant pathways connected to the genes in each gene set. Significant pathways of each gene set were further compared to identify common pathways between the sets (Fig.-11A).

Mutation validation using Sanger sequencing. Twenty-two point mutations from tumours and cfDNA of GBM patients were selected for validation of Sanger sequencing. Primers were designed using Primer3 (v. 0.4.0) ${ }^{163}$. All amplified PCR products were isolated using silica membrane spin column technique (NucleoSpin ${ }^{\circledR}$ Gel, PCR clean up kit Macherey-Nagel, Germany) and were eluted in $20 \mu 1$ of nuclease free water. PCR products were then processed for Sanger sequencing and the results were analysed using Basic Local Alignment Search Tool $\left(\text { BLAST }^{\circledR}\right)^{164}$ and Chromas ${ }^{\circledR} 2.6 .2^{165}$.

\section{TABLE AND FIGURE LEGENDS}

Table 1- The numbers of high impact alterations by each consequence type that was commonly identified in cell-free DNA (cfDNA) and tumour DNA (tDNA) of glioblastoma patients \#GB1, \#GB3, \#GB5, \#GB7 and \#GB13.

Table 2- A comparison between high impact mutations identified in five glioblastoma patients (\#GB1, \#GB3, \#GB5, \#GB7 and \#GB13) and genes reported in the literature as commonly mutated in glioblastoma.

Table 3- The 50 most frequently mutated genes in 291 glioblastoma patients in The Cancer Genome Atlas database, studied by Brennan, Cameron W., et al. (2013) and identified in our five glioblastoma patients (\#GB1, \#GB3, \#GB5, \#GB7 and \#GB13). 
Table 4- Druggable fusion genes and their targeted drugs identified in glioblastoma samples archived from The Cancer Genome Atlas database; cell-free (cfDNA), tumour DNA and germline DNA of glioblastoma patients, and cfDNA of healthy controls cfDNA.

Figure 1- Different sizes of cell-free DNA found in the blood as a result of apoptosis and necrosis.

Figure 2- Cell-free DNA concentrations in glioma patients vs. healthy controls.

Figure 3- Bioanalyzer assay electropherograms of cell-free DNA before and after the next-generation sequencing library preparation step.

Figure 4- Variant analysis method used to identify high impact variants.

Figure 5- Percentage distribution of high impact alterations across 58 glioma related genes (from Table 2) by 5 consequence types studied in glioblastoma patients \#GB1, \#GB3, \#GB5, \#GB7 and \#GB13.

Figure 6- Frequently occurring fusion genes studied in 20 glioblastoma patient's tDNA and respective germline DNA archived from The Cancer Genome Atlas database.

Figure 7- Twenty fusion genes studied in glioblastoma patients from The Cancer Genome Atlas (figure 5) also analysed in cell-free DNA, tumour DNA and germline DNA of glioblastoma patient \#GB1, \#GB3, \#GB5, \#GB7 and \#GB13.

Figure 8- Twenty fusion genes studied in glioblastoma patients from The Cancer Genome Atlas (figure5) also analysed in cell-free DNA of 9 glioblastoma patients and 9 healthy controls.

Figure 9- Druggable fusion genes identified in glioblastoma samples archived from The Cancer Genome Atlas database.

Figure 10- Gene set enrichment analysis study.

Figure 11- Mutation validation by Sanger sequencing. 
bioRxiv preprint doi: https://doi.org/10.1101/2020.02.25.963975; this version posted February 26, 2020. The copyright holder for this preprint (which was not certified by peer review) is the author/funder. All rights reserved. No reuse allowed without permission.

Table 1 । The numbers of high impact alterations by each consequence type that were commonly identified in cell-free DNA (cfDNA) and tumour DNA (tDNA) of glioblastoma patients \#GB1, \#GB3, 782 \#GB5, \#GB7 and \#GB13

\begin{tabular}{|c|c|c|c|c|c|c|c|c|c|c|}
\hline \multirow{3}{*}{$\begin{array}{l}\text { Consequence type } \\
\text { (Sequence Ontology term) }\end{array}$} & \multicolumn{10}{|c|}{$\begin{array}{l}\text { The number of high impact alterations commonly identified in cfDNA and } \\
\text { tDNA of each glioblastoma patient }\end{array}$} \\
\hline & \multicolumn{2}{|c|}{$\begin{array}{l}\text { GBM } \\
\text { Patient \#GB1 }\end{array}$} & \multicolumn{2}{|c|}{$\begin{array}{l}\text { GBM } \\
\text { Patient \#GB3 }\end{array}$} & \multicolumn{2}{|c|}{$\begin{array}{l}\text { GBM } \\
\text { Patient \#GB5 }\end{array}$} & \multicolumn{2}{|c|}{$\begin{array}{l}\text { GBM } \\
\text { Patient \#GB7 }\end{array}$} & \multicolumn{2}{|c|}{$\begin{array}{l}\text { GBM } \\
\text { Patient \#GB13 }\end{array}$} \\
\hline & count & $\%$ & count & $\%$ & count & $\%$ & count & $\%$ & count & $\%$ \\
\hline splice_donor_variant & 1 & 0.0 & 2 & 0.0 & 5 & 0.0 & 2 & 0.0 & 0 & 0.0 \\
\hline splice_acceptor_variant & 0 & 0.0 & 0 & 0.0 & 1 & 0.0 & 1 & 0.0 & 0 & 0.0 \\
\hline stop-gained & 0 & 0.0 & 1 & 0.0 & 1 & 0.0 & 0 & 0.0 & 0 & 0.0 \\
\hline missense_variant & 5 & 0.0 & 2 & 0.0 & 21 & 0.0 & 5 & 0.0 & 1 & 0.0 \\
\hline splice_region_variant & 8 & 0.0 & 9 & 0.0 & 37 & 0.1 & 10 & 0.0 & 6 & 0.0 \\
\hline synonymous_variant & 2 & 0.0 & 3 & 0.0 & 21 & 0.0 & 4 & 0.0 & 5 & 0.0 \\
\hline 5_prime_UTR_variant & 30 & 0.1 & 18 & 0.1 & 148 & 0.2 & 45 & 0.1 & 25 & 0.1 \\
\hline 3_prime_UTR_variant & 244 & 0.7 & 219 & 0.8 & 648 & 0.9 & 293 & 0.9 & 190 & 0.8 \\
\hline non_coding_transcript_exon_variant & 400 & 1.1 & 352 & 1.3 & 1082 & 1.5 & 473 & 1.4 & 290 & 1.3 \\
\hline intron_variant & 16989 & 47.3 & 12707 & 47.5 & 33637 & 47.6 & 15795 & 48.4 & 10780 & 46.5 \\
\hline upstream_gene_variant & 1327 & 3.7 & 1102 & 4.1 & 3417 & 4.8 & 1470 & 4.5 & 997 & 4.3 \\
\hline downstream_gene_variant & 1,254 & 3.5 & 992 & 3.7 & 2778 & 3.9 & 1300 & 4.0 & 824 & 3.6 \\
\hline TF_binding_site_variant & 68 & 0.2 & 62 & 0.2 & 224 & 0.3 & 86 & 0.3 & 65 & 0.3 \\
\hline regulatory_region_variant & 1545 & 4.3 & 1257 & 4.7 & 3702 & 5.2 & 1554 & 4.8 & 1059 & 4.6 \\
\hline intergenic_variant & 14017 & 39.1 & 10000 & 37.4 & 24929 & 35.3 & 11614 & 35.6 & 8954 & 38.6 \\
\hline
\end{tabular}

783 
bioRxiv preprint doi: https://doi.org/10.1101/2020.02.25.963975; this version posted February 26, 2020. The copyright holder for this preprint (which was not certified by peer review) is the author/funder. All rights reserved. No reuse allowed without permission.

Table 2 A comparison between high impact mutations identified in five glioblastoma patients (\#GB1, \#GB3, \#GB5, \#GB7 and \#GB13) and genes reported in the literature as commonly mutated in glioblastoma. Column 1 lists 58 genes that have been found to be commonly mutated in glioblastoma. Columns 2,3 and 4 present data about glioblastoma from 3 major studies (Piccioni, David E., et al. 2019, Gao, Jianjiong, et al. 2013, Tate, John G., et al. 2019). The percentages inside the parentheses indicate the proportions of glioblastoma patients that showed a mutation in corresponding genes in column-1. The numbers outside the parenthesis indicate the total number of glioblastoma patients who were tested in the study. Columns 5,6,7,8 and 9 show the high impact mutations that were identified, commonly in cfDNA and tumour DNA, and in corresponding genes in column 1 in glioblastoma patients \#GB1, \#GB3, \#GB5, \#GB7 and \#GB13, respectively.

785

786

787

788

789

790

791

792

793

794

795

796

797

798

799

800

801

802

803

804

805

806

807

808

809

810

811

812

813

814

815

816

817

818

819

820

821

822

823

824

825

826

827

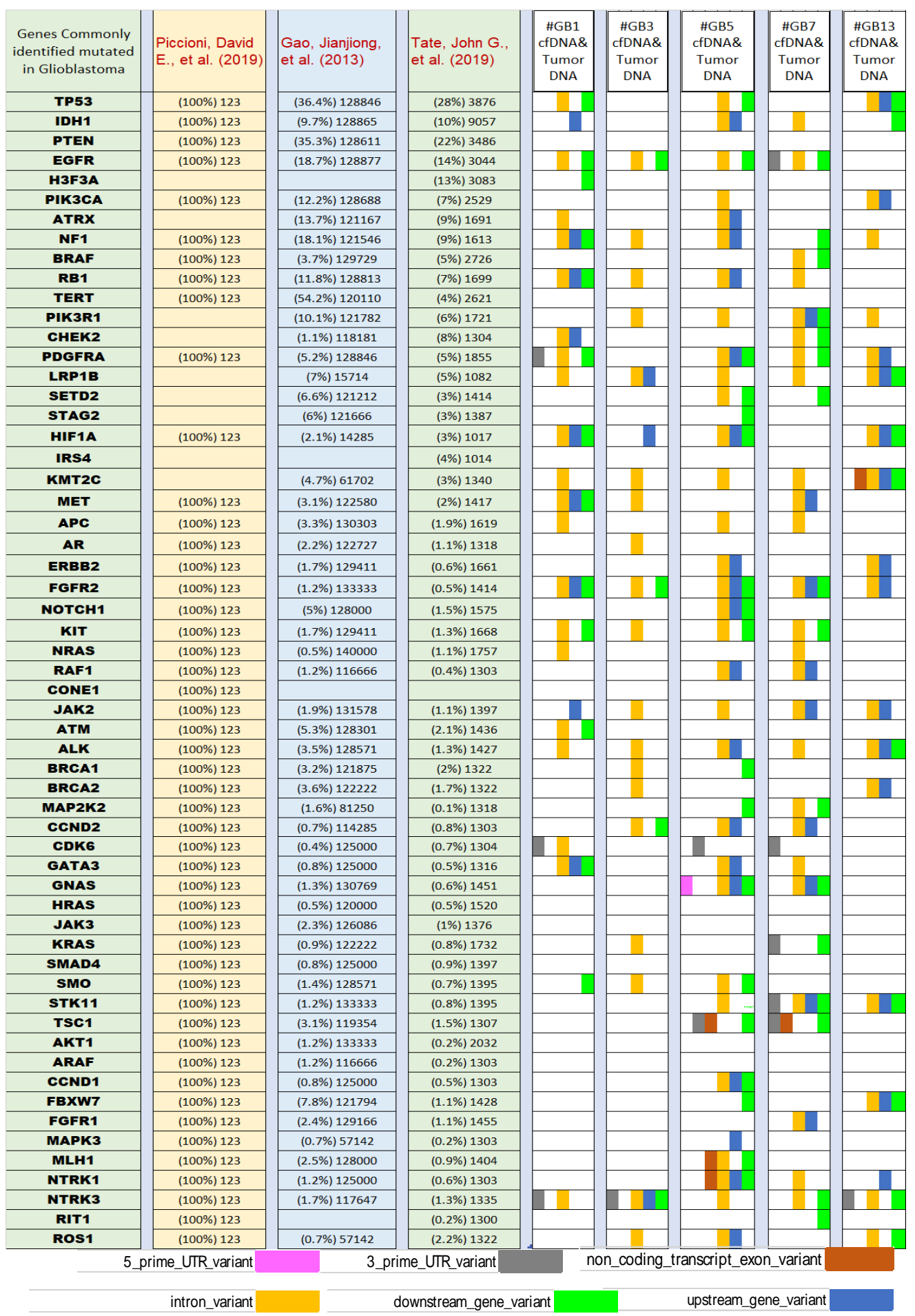


bioRxiv preprint doi: https://doi.org/10.1101/2020.02.25.963975; this version posted February 26, 2020. The copyright holder for this preprint (which was not certified by peer review) is the author/funder. All rights reserved. No reuse allowed without permission.

Table 3 The 50 most frequently mutated genes in 291 glioblastoma patients in the TCGA database, studied by Brennan, Cameron W., et al. (2013) and identified in our five glioblastoma patients (\#GB1, \#GB3, \#GB5, \#GB7 and \#GB13). Column 1 lists 50 genes that were identified as commonly mutated in 291 glioblastoma patients by Brennan, Cameron W., et al. (2013). Columns 2, 3, 4, 5 and 6 show the high impact mutations that were identified commonly in cfDNA and tumour DNA, and in the corresponding genes in column-1 in glioblastoma patients \#GB1, \#GB3, \#GB5, \#GB7 and \#GB13, respectively.

828

829

830

831

832

833

834

835

836

837

838

839

840

841

842

843

844

845

846

847

848

849

850

851

852

853

854

855

856

857

858

859

860

861

862

863

864

865

866

867

868

869

870

871

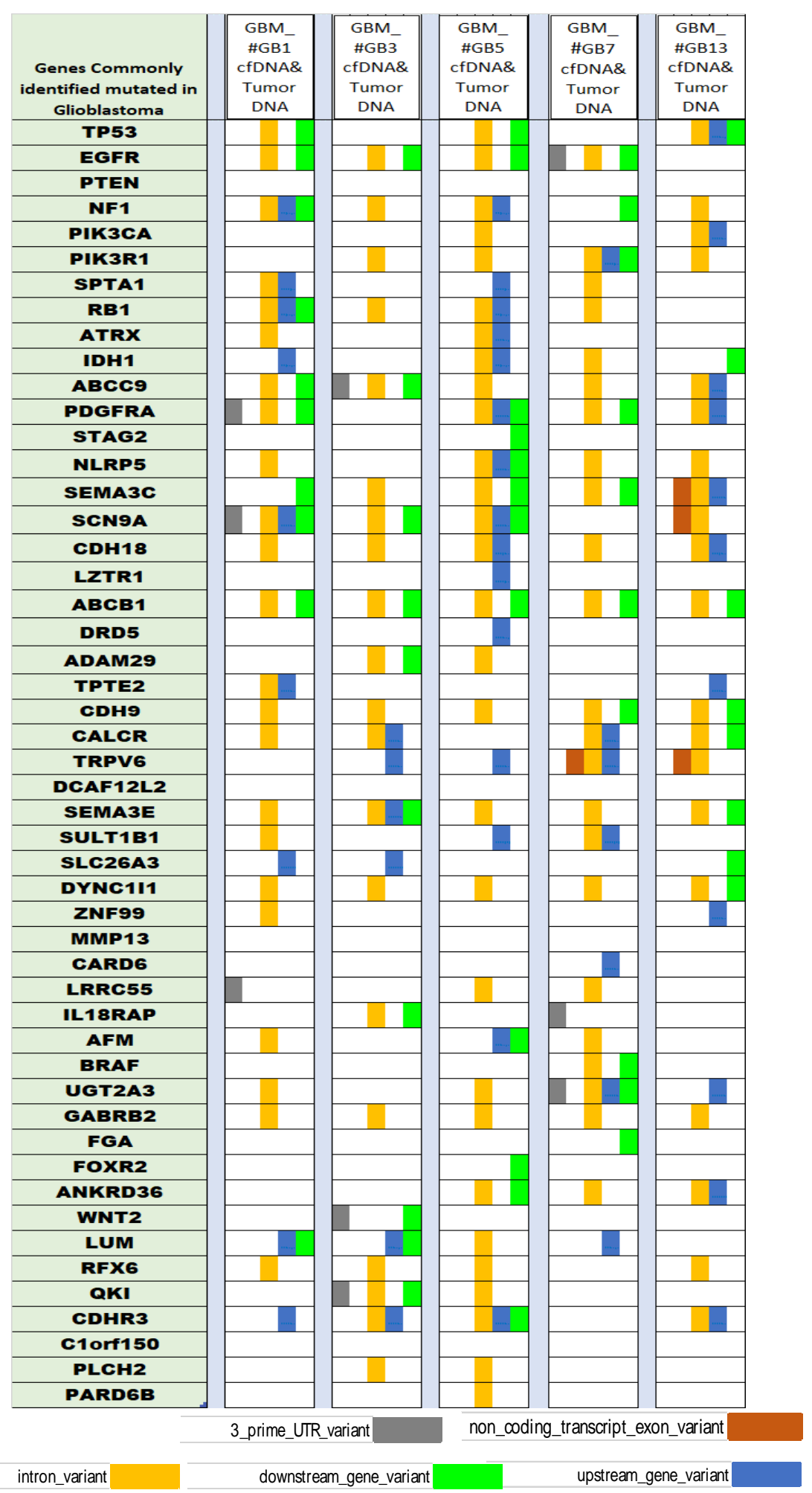


bioRxiv preprint doi: https://doi.org/10.1101/2020.02.25.963975; this version posted February 26, 2020. The copyright holder for this preprint (which was not certified by peer review) is the author/funder. All rights reserved. No reuse allowed without permission.

Table 4 । Druggable fusion genes and their targeted drugs identified in glioblastoma samples archived from The Cancer Genome Atlas (TCGA) database; cell-free DNA (cfDNA), tumour DNA (tDNA) and germline DNA of glioblastoma patients, and cfDNA of healthy controls.

\begin{tabular}{|c|c|c|c|}
\hline $\begin{array}{l}\text { Druggable } \\
\text { Fusion genes }\end{array}$ & Targeted drugs & Junction_Type & $\begin{array}{l}\text { Identified in glioblastoma patients or healthy } \\
\text { controls }\end{array}$ \\
\hline $\begin{array}{l}\text { KMT2A- } \\
\text { FLNA }\end{array}$ & Daunorubicin & intron-exon & $\begin{array}{l}\text { TCGA-32-1970(tumour and germline DNA); } \\
\text { TCGA-06-0157 (tDNA); } \\
\text { TCGA-27-1831 (germline DNA); } \\
\text { TCGA-26-5132 (tDNA); } \\
\text { TCGA-27-2523 (tDNA); } \\
\text { TCGA-02-2485 (germline DNA); } \\
\text { TCGA-26-5135 (tDNA); } \\
\text { TCGA-06-5411 (tDNA); TCGA-15-1444 } \\
\text { (germline DNA); }\end{array}$ \\
\hline FGFR1-BCR & $\begin{array}{l}\text { Dasatinib; Nilotinib; Ponatinib; } \\
\text { Ruxolitinib;Imatinib; TKIs; Bosutinib; } \\
\text { Sorafenib; AZD0530; AZD4547; BGJ398; } \\
\text { Debio1347; Erdafitinib }\end{array}$ & exon-exon & TCGA-06-5411 (tDNA) \\
\hline TPM3-ROS1 & Crizotinib, entrectinib, larotrectinib & exon-exon & TCGA-15-1444 (germline DNA) \\
\hline TFG-ALK & $\begin{array}{l}\text { Crizotinib; entrectinib, larotrectinibCeritinib; } \\
\text { PF2341066; TAE684; novel ALK inhibiors; } \\
\text { Alectinib; Brigatinib; Lorlatinib; foretinib }\end{array}$ & exon-exon & TCGA-26-5135 (tDNA) \\
\hline MSN-ALK & $\begin{array}{l}\text { Crizotinib; entrectinib, larotrectinib, Ceritinib; } \\
\text { PF2341066; TAE684; novel ALK inhibiors; } \\
\text { Alectinib; Brigatinib; Lorlatinib }\end{array}$ & exon-exon & TCGA-26-5135 (tDNA) \\
\hline $\begin{array}{l}\text { MLLT1- } \\
\text { KMT2A }\end{array}$ & Daunorubicin & exon-exon & TCGA-06-5411 (tDNA) \\
\hline \multirow{2}{*}{ BCR-ABL1 } & \multirow{2}{*}{$\begin{array}{l}\text { Imatinib; Bosutinib; Dasatinib; Nilotinib; } \\
\text { Ponatinib; Asciminib; TKIs; Sorafenib }\end{array}$} & exon-exon & TCGA-27-2523 (tDNA) \\
\hline & & intron-exon & TCGA-15-1444 (germline DNA) \\
\hline $\begin{array}{l}\text { NIN- } \\
\text { PDGFRB }\end{array}$ & Imatinib & exon-exon & TCGA-02-2485 (germline DNA); \\
\hline $\begin{array}{l}\text { AKAP9- } \\
\text { BRAF }\end{array}$ & $\begin{array}{l}\text { Sorafenib; MEK inhibitors; } \\
\text { Binimetinib+Encorafenib; Cobimetinib; } \\
\text { Cobimetinib+Vemurafenib; Dabrafenib; } \\
\text { Dabrafenib+Trametinib; Trametinib; } \\
\text { Vemurafenib }\end{array}$ & exon-exon & TCGA-06-5411 (tDNA) \\
\hline $\begin{array}{l}\text { KMT2A- } \\
\text { MAML2 }\end{array}$ & Daunorubicin & exon-exon & TCGA-27-1831 (germline DNA) \\
\hline $\begin{array}{l}\text { FGFR1- } \\
\text { PLAG1 }\end{array}$ & $\begin{array}{l}\text { AZD4547; BGJ398; Debio1347; Erdafitinib; } \\
\text { Ponatinib }\end{array}$ & exon-exon & TCGA-26-5135 (tDNA) \\
\hline KIF5B-RET & Cabozantinib; Vandetanib & exon-exon & TCGA-27-2523 (tDNA), TCGA-32-1970 (tDNA) \\
\hline $\begin{array}{l}\text { EWSR1- } \\
\text { ATF1 }\end{array}$ & PARP inhibitors & exon-exon & TCGA-15-1444 (germline DNA) \\
\hline $\begin{array}{l}\text { TPM3- } \\
\text { NTRK1 }\end{array}$ & $\begin{array}{l}\text { pan-TRK inhibitor; Entrectinib; Larotrectinib; } \\
\text { Crizotinib }\end{array}$ & exon-exon & TCGA-26-5132 (tDNA) \\
\hline RARA-PML & ATRA + arsenic trioxide & exon-exon & TCGA-26-5135 (tDNA) \\
\hline $\begin{array}{l}\text { GOLGA5- } \\
\text { RET }\end{array}$ & Cabozantinib; Vandetanib & exon-exon & TCGA-27-2523 (tDNA), GBM_\#IA (cfDNA) \\
\hline \multirow{2}{*}{$\begin{array}{l}\text { COL1A1- } \\
\text { PDGFB }\end{array}$} & \multirow{2}{*}{ Imatinib } & exon-exon & TCGA-26-5135 (tDNA) \\
\hline & & exon-intron & TCGA-32-1970 (tDNA) \\
\hline ABL1-BCR & $\begin{array}{l}\text { Imatinib; Dasatinib; Nilotinib; Ponatinib; } \\
\text { Bosutinib; Ruxolitinib }\end{array}$ & intron-exon & TCGA-15-1444 (germline DNA) \\
\hline $\begin{array}{l}\text { FLI1- } \\
\text { EWSR1 }\end{array}$ & PARP inhibitors; TK216 & intron-exon & TCGA-02-2485 (germline DNA); \\
\hline NPM1-ALK & Crizotinib, entrectinib, larotrectinib & intron-exon & $\begin{array}{l}\text { TCGA-15-1444 (germline DNA), } \\
\text { Healthy-Ctrl_\#TS_0(cfDNA) }\end{array}$ \\
\hline \multirow[b]{2}{*}{$\begin{array}{l}\text { NIN- } \\
\text { PDGFRB }\end{array}$} & \multirow{2}{*}{ Imatinib } & exon-exon & $\begin{array}{l}\text { GBM_\#GB7 (germline DNA), TCGA-02-2485 } \\
\text { (germline DNA) }\end{array}$ \\
\hline & & exon-intron & TCGA-26-5132 (tDNA) \\
\hline
\end{tabular}


bioRxiv preprint doi: https://doi.org/10.1101/2020.02.25.963975; this version posted February 26, 2020. The copyright holder for this preprint (which was not certified by peer review) is the author/funder. All rights reserved. No reuse allowed without permission.

873

874

875

876

877

878

879

880

881

882

883

884

885

886

887

888

889

890

891

892

893

894

895

896

897

898

899

900

901

902

903

904

905

906

907

908

909

910

911

912

913

\begin{tabular}{|l|l|l|l|}
\hline $\begin{array}{l}\text { TENM4- } \\
\text { NRG1 }\end{array}$ & Lapatinib & intron-exon & GBM_\#GB3 (germline DNA) \\
\hline SDC4-ROS1 & Crizotinib, entrectinib, larotrectinib & exon-exon & GBM_\#VIIIA (cfDNA) \\
\hline
\end{tabular}

Fig. 1 Different sizes of cfDNA found in the blood as a result of apoptosis and necrosis.

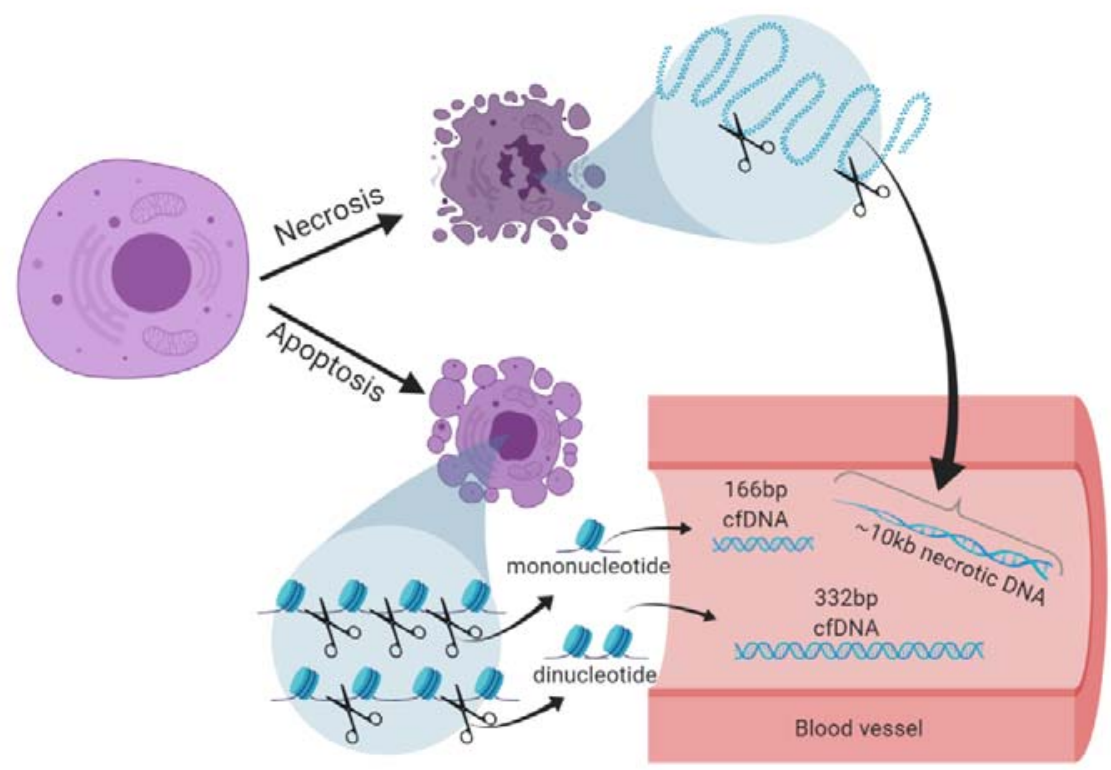

Fig. 2 Cell-free DNA (cfDNA) concentrations in glioma cancer patients vs. healthy controls. The graph shows comparatively high cfDNA concentrations in $1 \mathrm{ml}$ plasma of 25 glioblastoma patients (orange), 2 lowgrade glioma patients (yellow) and 14 control samples (green).

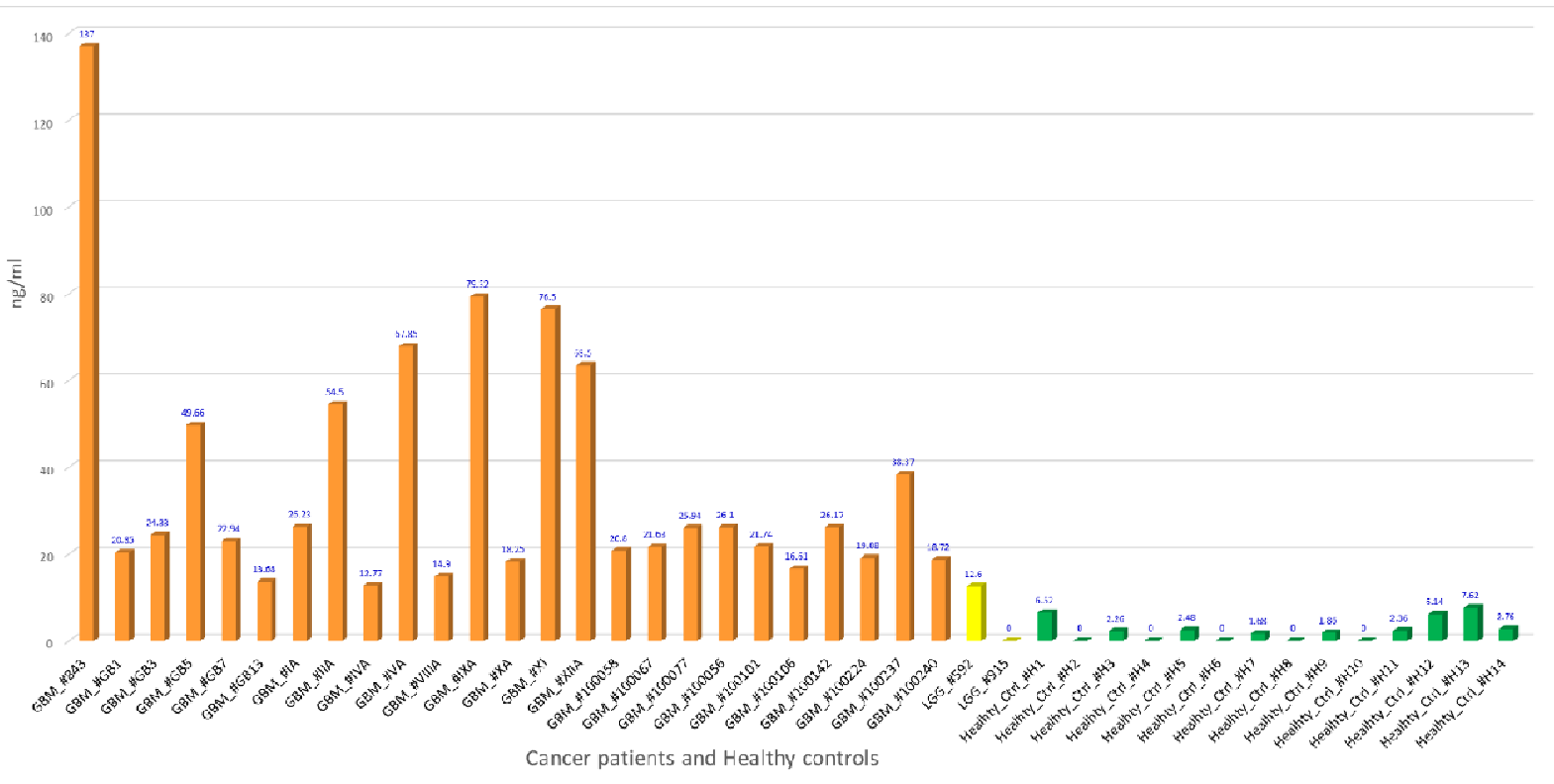


914

915

916

917

918

Fig. 3 Bioanalyzer assay electropherograms of cell-free DNA (cfDNA) before and after the nextgeneration sequencing (NGS) library preparation step. (A) cfDNA isolated from glioblastoma patient \#843, enriched at fragment size 166bp. (B) cfDNA NGS library enriched at the expected fragment size $291 \mathrm{bp}$ (corresponding to 166bp of cfDNA + 125bp NGS adapters), confirming its successful NGS library preparation.

\section{Before library preparation}

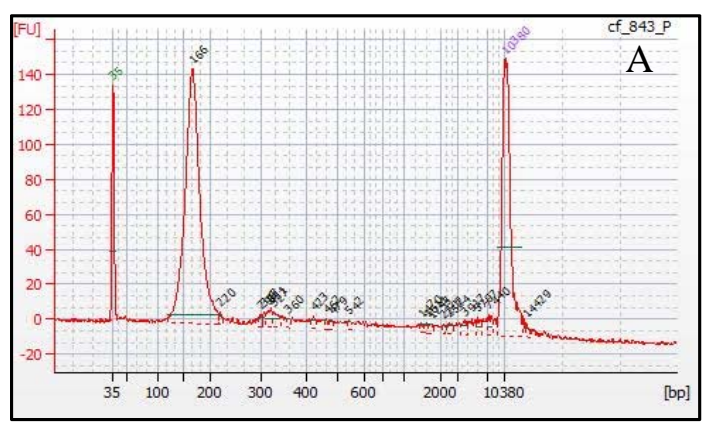

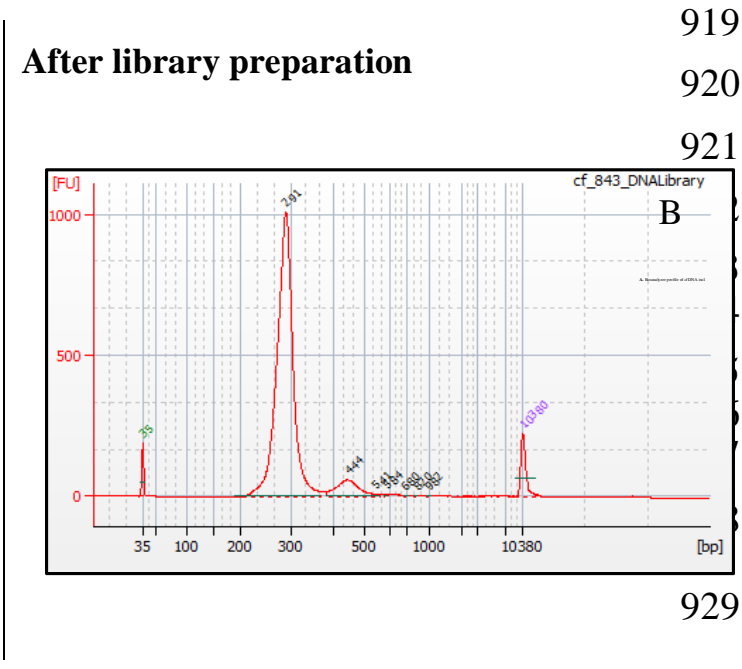

930

931

932

933

934

935

936

937

938

939

940

941

942

943

944

945

946

947

948

949

950

951

952
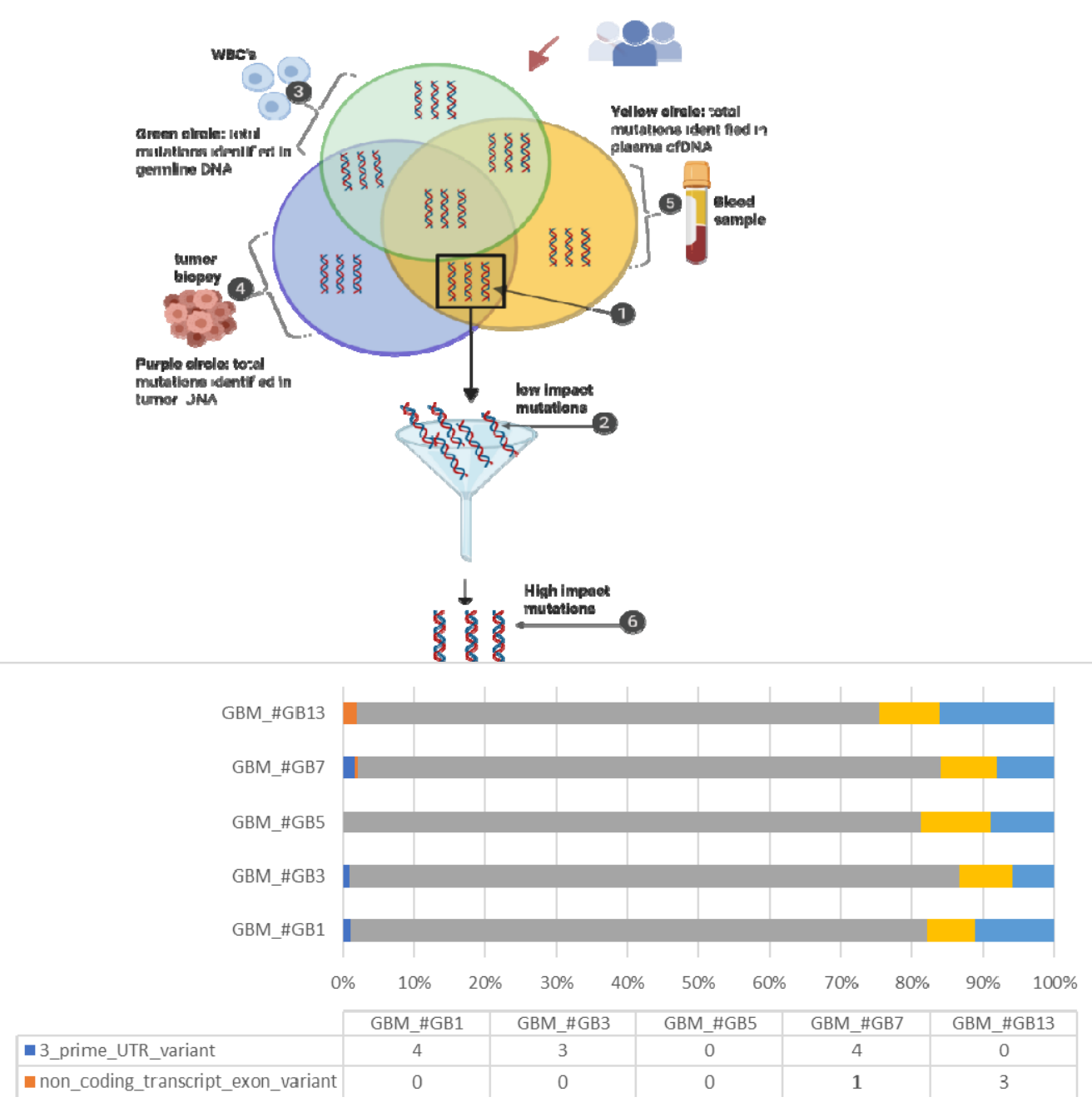
bioRxiv preprint doi: https://doi.org/10.1101/2020.02.25.963975; this version posted February 26, 2020. The copyright holder for this preprint (which was not certified by peer review) is the author/funder. All rights reserved. No reuse allowed without permission.

953

954

955

956

957

958

959

960

961

962

963

964

965

966 
Fig. 6 Frequently occurring fusion genes studied in DNA, tumour DNA and respective germline DNA of 20 glioblastoma patients, archived from The Cancer Genome Atlas database.

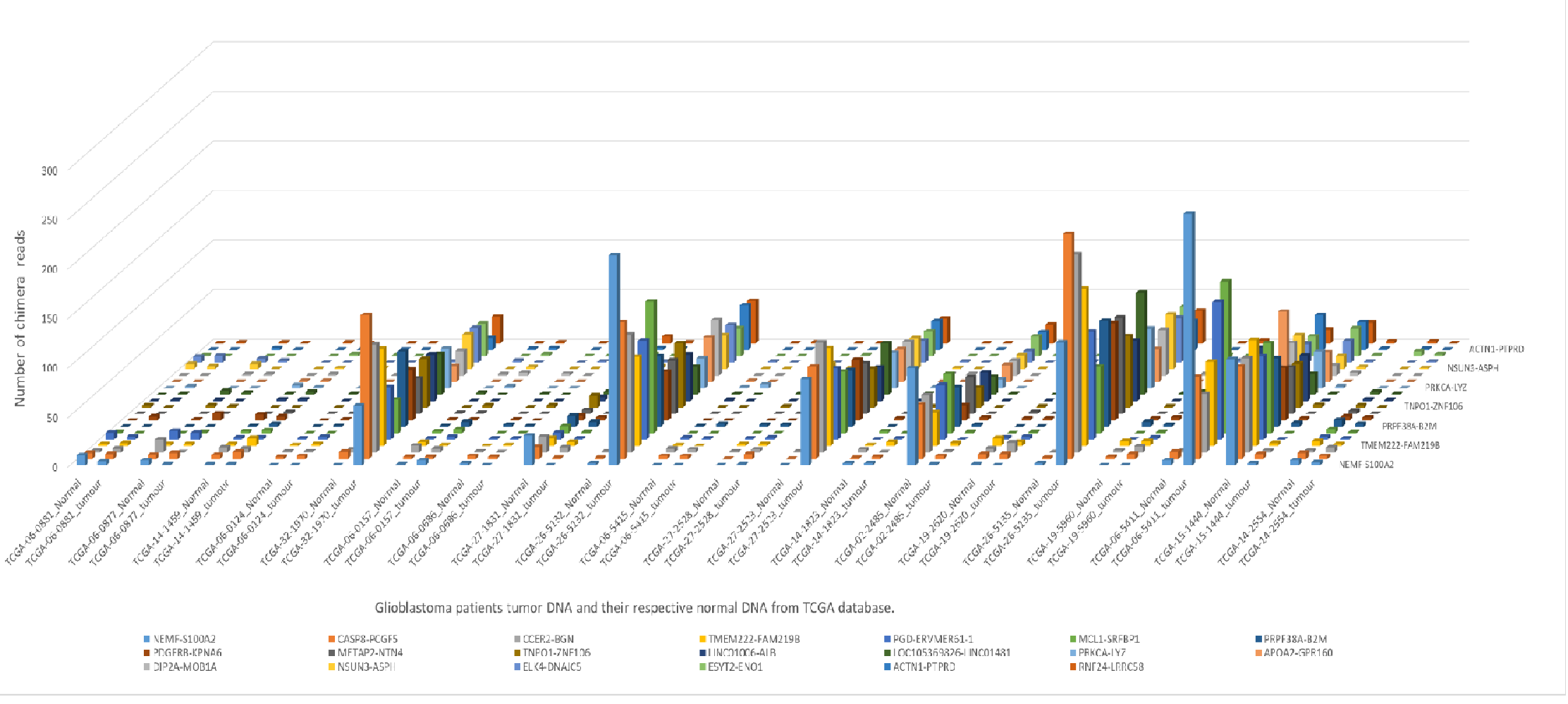

970
971

972

973

974

975 
Fig. 7 Twenty fusion genes studied in glioblastoma patients from The Cancer Genome Atlas database (figure 5); and also analysed in cell-free DNA, tumour DNA and germline DNA of glioblastoma patients \#GB1, \#GB3, \#GB5, \#GB7 and \#GB13.

976

977

978

979

980

981

Fig. 8 Twenty fusion genes studied in glioblastoma patients from The Cancer Genome Atlas database (figure 5), and also analysed in cell-free DNA of 9 glioblastoma patients and 9 healthy controls.

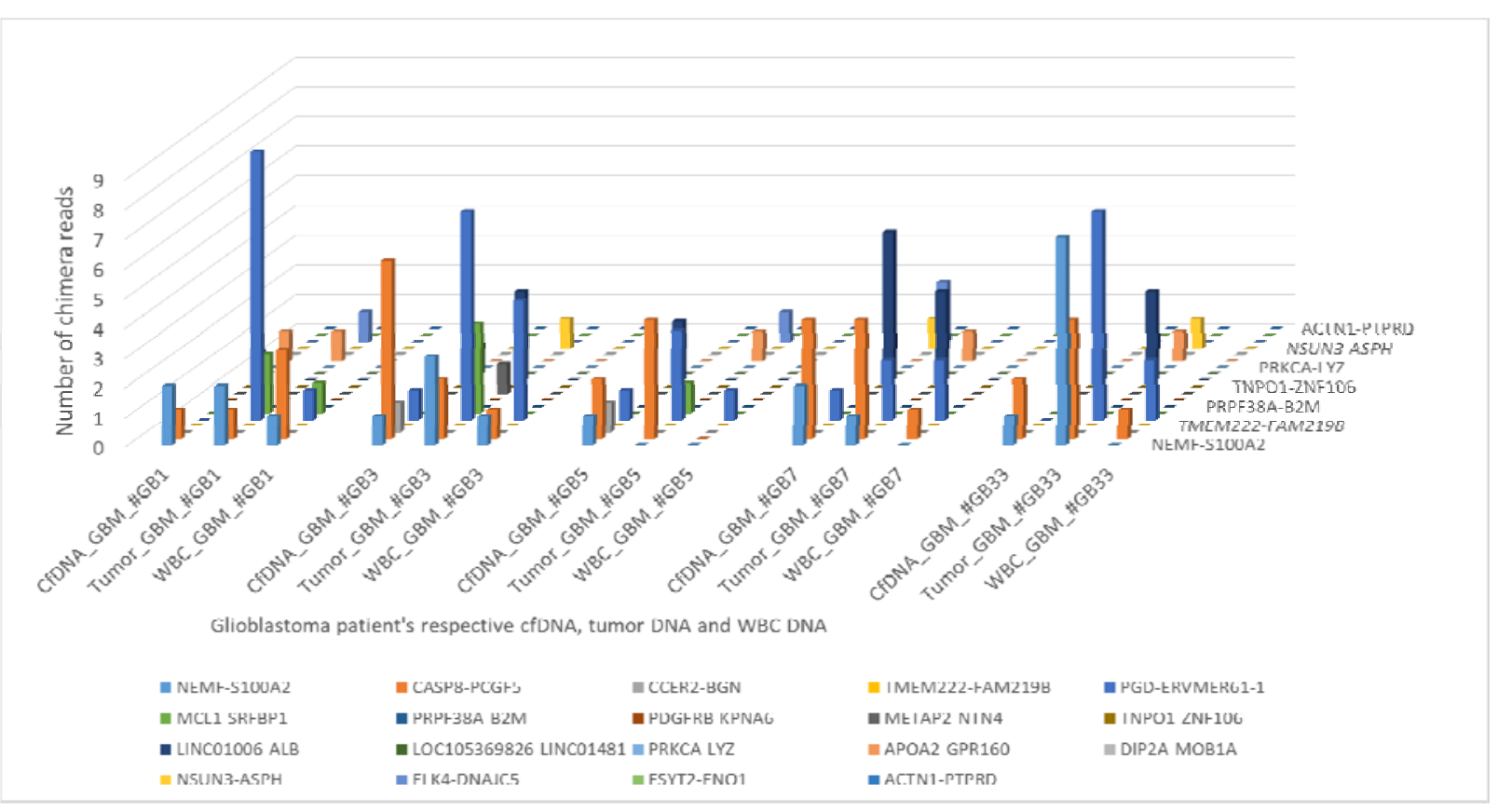

Glioblastoma patient's respective cfDNA, tumor DNA and WBC DNA

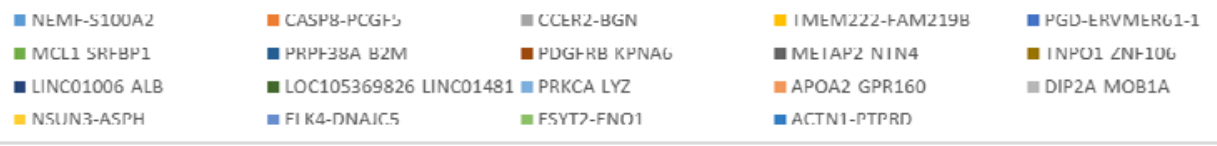

(1)

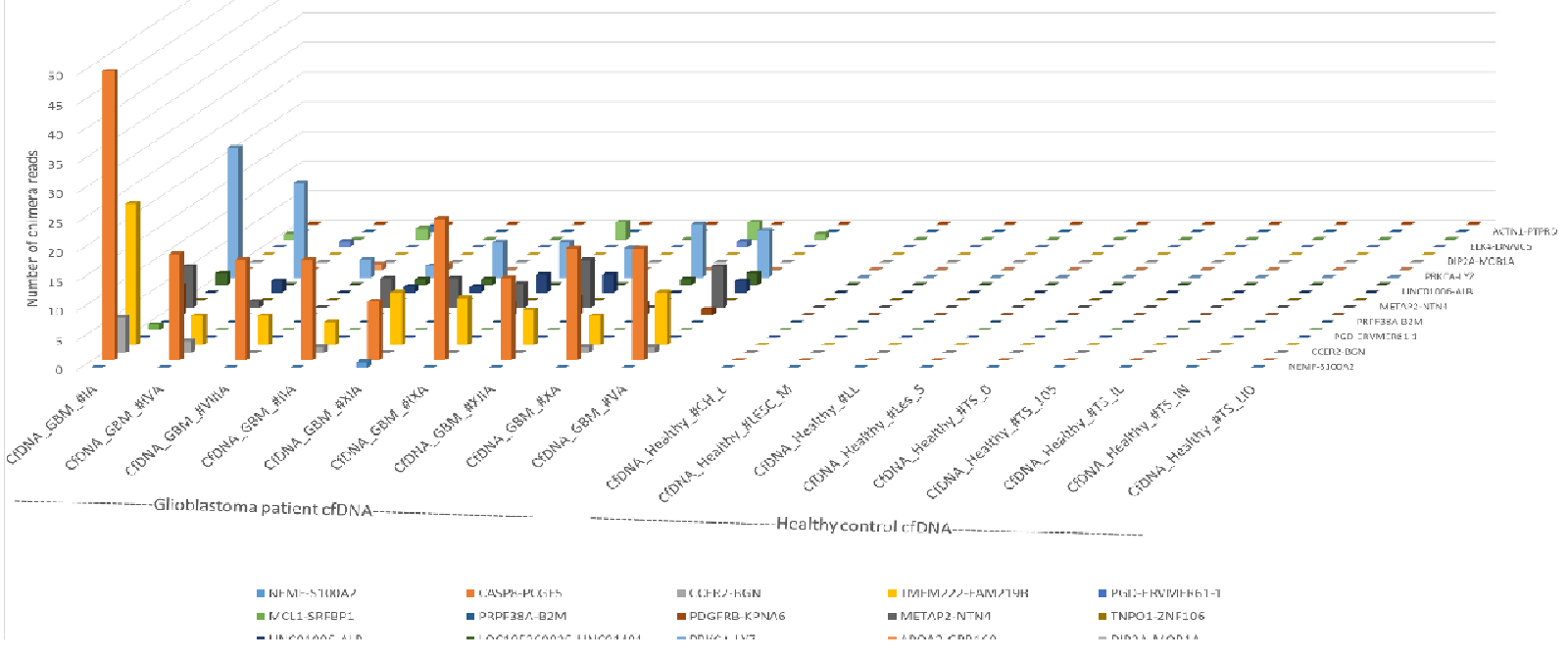


Fig. 9 Druggable fusion genes identified in glioblastoma samples archived from The Cancer Genome Atlas database.

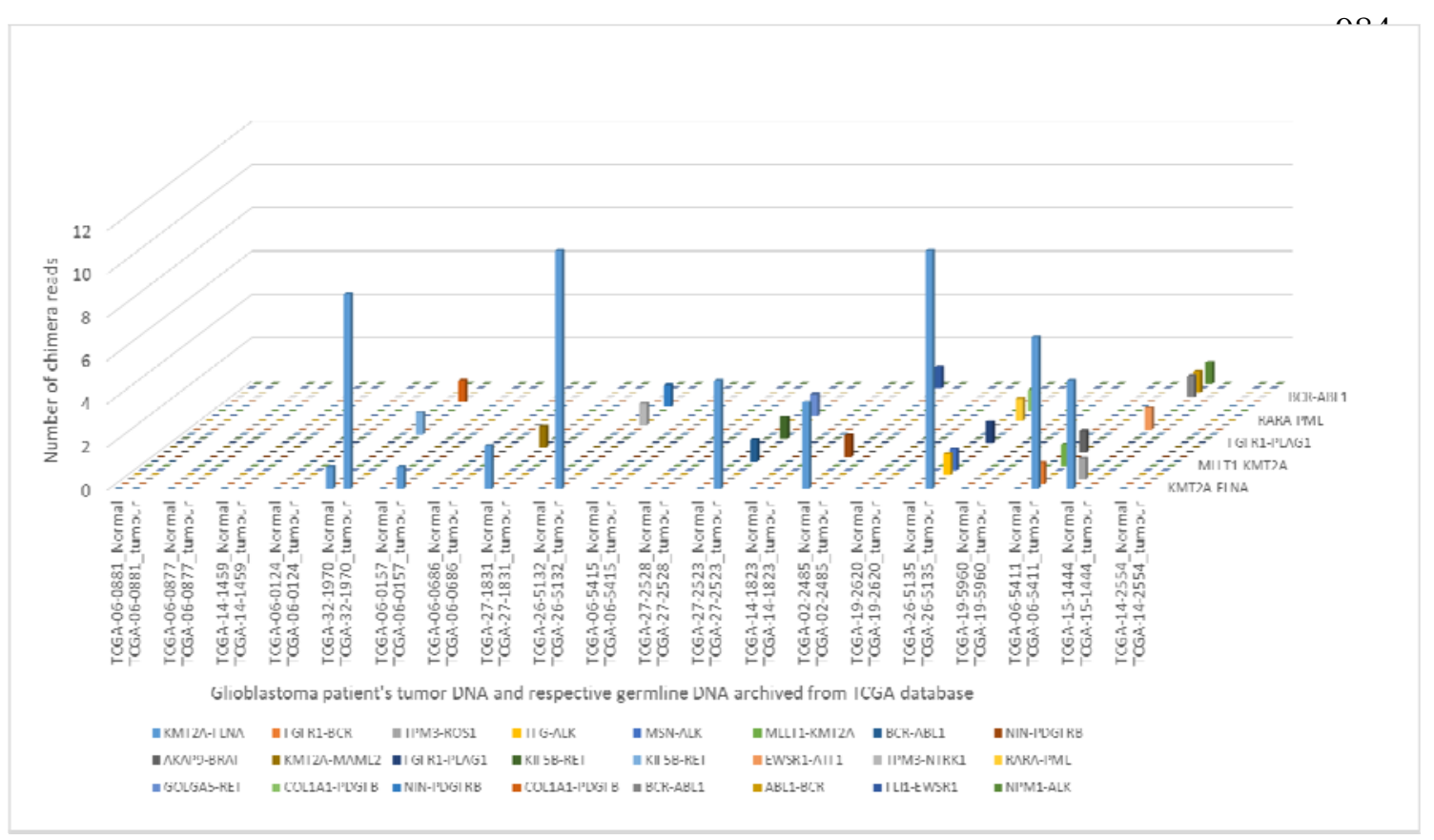

Fig. 10 Gene set enrichment analysis study

A. Gene set enrichment analysis flowchart. A total of 96 genes that were identified as frequently mutated in glioblastoma (from tables $2 \& 3$ ); and 40 genes that are glioblastoma (from figures $6,7 \& 8$ ) were analysed against human online analysis tool webgestalt $\mathbf{B}$. The bar graph shows 6 signific gene was involved from both: frequently mutated glioblastoma $g_{r}$ as frequent fusions in glioblastoma.

A ently observed as fusions in

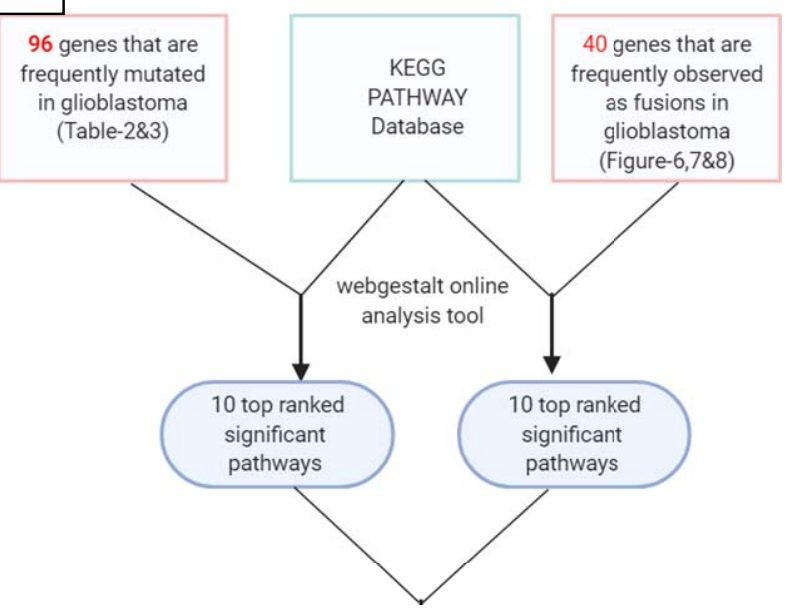


1008

1009

1010

1011

1012

1013

1014

1015

1016

1017

1018

1019

1020

1021

1022

1023

1024

1025

1026

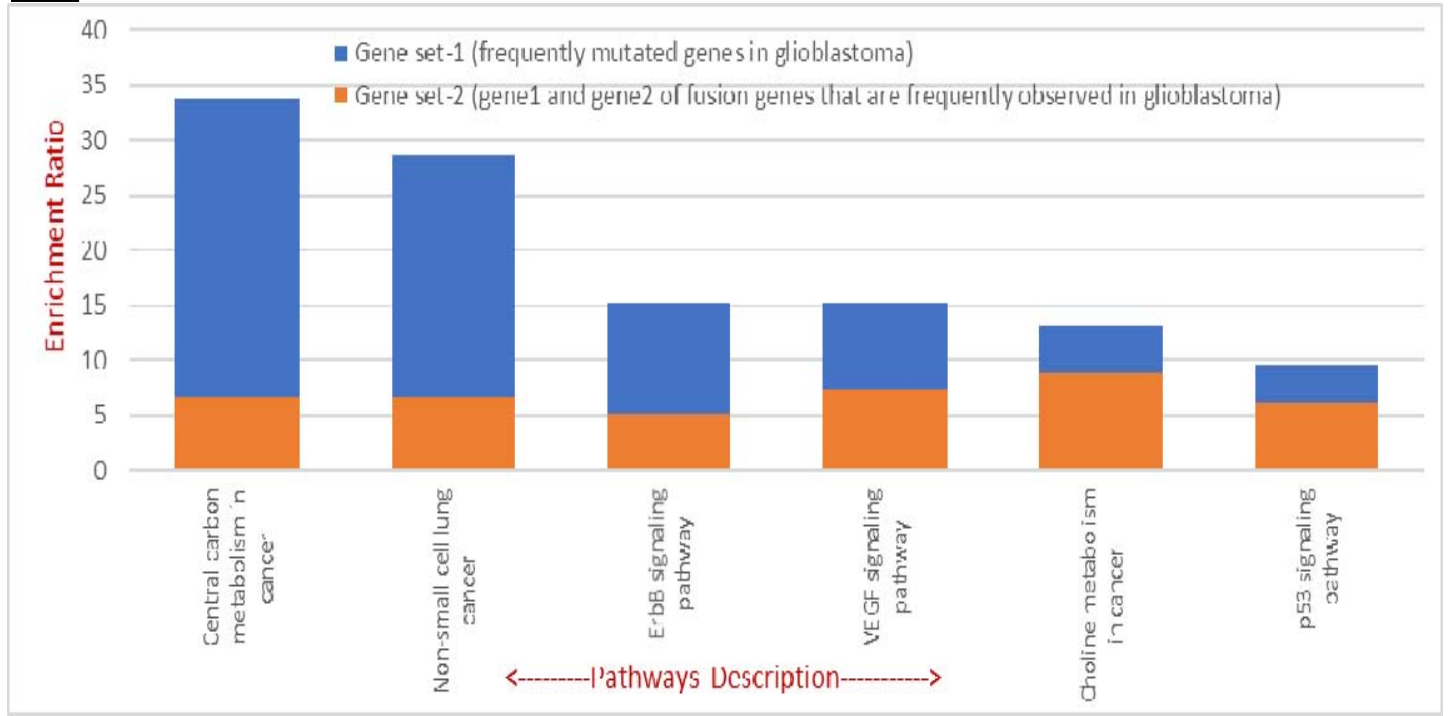

\section{$\mathbf{B}$}


Fig. 11 Mutation validation by Sanger sequencing. PDGFRA mutation 'exon12:c.A1701G' validation using Sanger sequencing, A- Sanger sequence visualization in Chromas ${ }^{\circledR}$ software, B- BLAST result of the Sanger sequence when compared with reference human genome hg38.
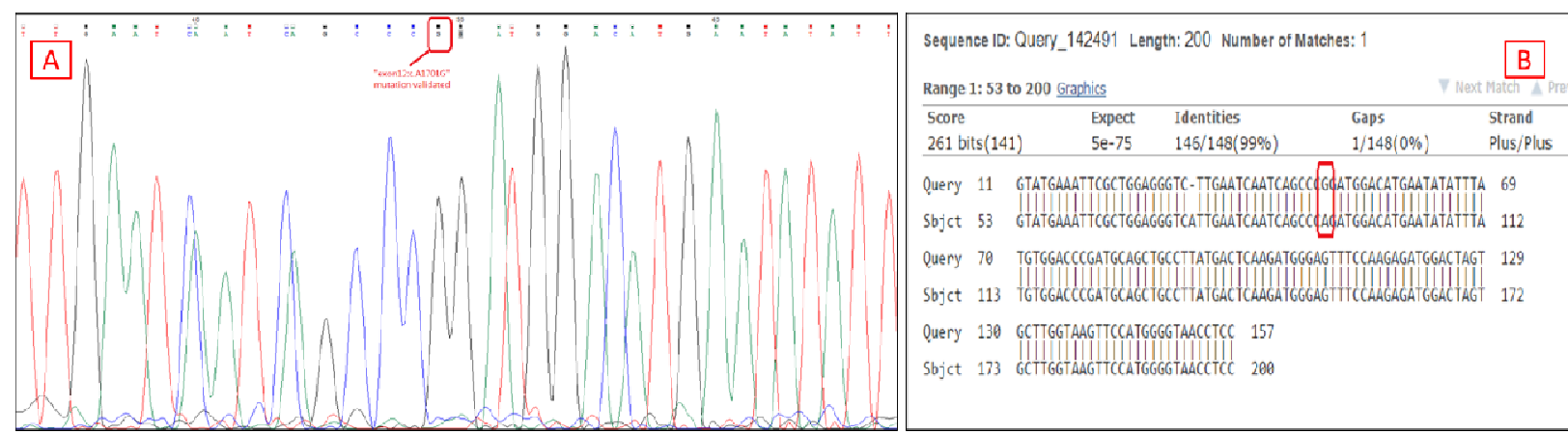